\title{
Contribuições de um Plugin do tipo Report para a Identificação do Risco de Evasão no AVA Moodle com base em Visualização de Dados
}

\author{
Contributions of the report-type plugin for dropout risk identification in Moodle VLE based \\ on data visualization
}

Maria Tatiane de Souza Brito Universidade Federal da Paraíba tatiane.brito@ifpb.edu.br

Alex Sandro Rodrigues Barbosa Instituto Federal da Paraíba alex.barbosa@academico.ifpb.edu.br

\author{
Francisco Petrônio Alencar de \\ Medeiros \\ Instituto Federal da Paraíba \\ petronio@ifpb.edu.br
}

\author{
Ed Porto Bezerra \\ Universidade Federal da \\ Paraíba \\ ed@ufpb.br
}

\begin{abstract}
Resumo
Este trabalho pertence ao campo de pesquisa educacional, conhecido como Learning Analytics, e tem como objetivo analisar a contribuição de indicadores sociais, cognitivos e comportamentais da aprendizagem dos alunos, criados com base em dados do Ava Moodle, para auxiliar professores, tutores e coordenadores de cursos on-line na identificação de alunos em risco de evasão. Os AVAs geram relatórios e logs sobre as atividades dos alunos, todavia eles geralmente são de difícil compreensão para tutores, professores e coordenadores de curso, o que dificulta a identificação de problemas de evasão, entre outros, de forma mais objetiva. Diante disso, acredita-se que a utilização de uma solução que colete dados de indicadores referentes aos acessos, às interações e às notas dos alunos em um AVA, apresentando-os por meio de infográficos, pode ajudar aos agentes acima citados a identificar alunos que possam estar em vias de abandonar um curso a distância. Para tanto, foi concebido e implementado um plugin do tipo report (relatório) para o AVA Moodle, contendo funcionalidades de filtros, envio de notificações e gráficos interativos, gerados pela ferramenta Google Charts. Para avaliar esse plugin, foram feitas análises qualitativas através da aplicação dessa ferramenta com o grupo focal formado desses profissionais de cursos a distância. Concluiu-se, então, que o plugin proporciona uma melhoria na percepção desse grupo em relação aos dados dos alunos que estão em risco de evasão, em comparação com os logs e relatórios nativos do Moodle. Palavras-Chave: Evasão, Moodle, Learning Analytics, Visualização de dados, Indicadores.
\end{abstract}

\begin{abstract}
This work belongs to the field of educational research known as Learning Analytics and aims to analyze the contribution of social, cognitive and behavioral indicators of student learning, based on Ava Moodle data, to help tutors and managers of online courses in identification of students at risk of circumvention. AVAs generate reports and logs on student activities, however, they are often difficult to understand for tutors, teachers and educational managers. Thus, they do not allow the identification of evasion problems more objectively. Therefore, it is believed that the use of a solution that collects data of indicators related to the accesses, interactions and notes of the students in an AVA and presents them through infographic, can help teachers, tutors and managers to identify students who can to leave a course at a distance. Therefore, a report plugin for the AVA Moodle was designed and implemented, containing filtering features, sending notifications and interactive graphics generated by the Google Charts tool. To evaluate this plugin, qualitative analyzes were carried out through a focus group with teachers, tutors and managers
\end{abstract}

Cite as: de Souza Brito, M. T., Medeiros, F. P. A de., Bezerra, E. P., \& Barbosa, A. S. R. (2020). Contributions of the report-type plugin for dropout risk identification in Moodle VLE based on data visualization (Contribuições de um Plugin do tipo Report para a Identificação do Risco de Evasão no AVA Moodle com base em Visualização de Dados). Brazilian Journal of Computers in Education (Revista Brasileira de Informática na Educação - RBIE), 28, 01-29. DOI: 10.5753/RBIE.2020.28.0.01 
of distance learning courses. It was concluded, then, that the plugin provides an improvement in the perception of these professionals on students who are at risk of avoidance, in comparison to the native logs and reports of Moodle. Keywords: Dropout, Moodle, Learning Analytics, Data Visualization, Indicators

\section{Introdução}

O desenvolvimento das Tecnologias da Informação e da Comunicação (TICs) e a expansão da Internet influenciaram o crescimento da modalidade de Educação a Distância (EAD). Ainda assim, a taxa de evasão dos alunos nos cursos dessa modalidade superou a dos cursos presenciais (KOSTOPOULOS, KOTSIANTIS e PINTELAS, 2015). Essa informação é corroborada pelo Relatório de 2016 da Associação Brasileira de Educação a Distância (ABED), que aponta que $58 \%$ das instituições que oferecem cursos EAD possuem uma faixa de evasão de $11 \%$ a $25 \%$, enquanto que as de cursos presenciais apresentam uma proporção de 6\% a 10\% (ABED, 2016).

Os Ambientes Virtuais de Aprendizagem (AVAs) - plataformas digitais que propiciam o ensino-aprendizagem na modalidade EAD - fornecem relatórios e logs, para que os professores e tutores possam acompanhar a aprendizagem e o desempenho dos alunos, estando aptos a identificar problemas como a evasão. Dobashi (2016) destaca, contudo, o fato de, além de muitos professores avaliarem como insatisfatória a capacidade desses sistemas, enquanto facilitadores da análise do histórico de aprendizagem dos alunos, a maioria deles não possui formação na área de Tecnologia da Informação. Esses relatórios geralmente se apresentam de forma pouco intuitiva, em formato tabular, com uma organização lógica fraca, que dificulta a compreensão dos registros de acessos e das interações dos alunos no AVA (MAZZA e DRIMITROVA, 2007). Isso torna o processo de acompanhamento desses estudantes muito manual, subjetivo, empírico e sujeito a falhas, dependendo primordialmente da experiência acadêmica e do envolvimento dos professores e tutores. Tendo em vista que os professores desempenham inúmeras atividades, estas ainda somadas à grande quantidade de estudantes por turma (nos cursos a distância), torna-se bastante difícil acompanhar e reconhecer as necessidades de cada um deles e identificar aqueles que realmente apresentam risco de evasão (COSTA e SANTOS, 2017).

Frente a este cenário, é crescente a busca por melhorias no acompanhamento dos alunos, por meio dos próprios dados do AVA, a fim de se perceberem problemas como baixo desempenho e evasão - este último foco deste artigo. O êxito do aluno no curso traz benefícios tanto para si quanto para a sociedade, que contará com mais pessoas qualificadas, e ainda para a instituição que o preparou. É, portanto, preponderante, para o sucesso dos cursos a distância ou mesmo híbridos, prover formas eficazes de monitoramento do aluno, que possibilitem reconhecer, nas turmas, cursistas que comecem a dar sinais de possível evasão, isso, evidentemente, aliado com ações de permanência. Cohen (2017) corrobora essa informação, quando afirma que um dos elementos-chave na redução das taxas de abandono escolar é a identificação rápida e precisa dos estudantes sob tal risco, o que exige a exploração de métodos eficientes, uma vez que, na EAD, tanto alunos como professores não estão em um ambiente face-a-face (COUTINHO et al., 2018).

Neste sentido, preocupando-se com a forma como os dados gerados pelos AVAs podem ser utilizados para melhorar o processo de ensino e aprendizagem dos alunos, surgiu a área conhecida como Learning Analytics. O termo ainda não possui uma tradução consagrada na literatura brasileira e, por isso, utilizaremos a forma em inglês ou abreviada (LA) no decorrer deste trabalho. Os autores Cechinel, Einhardt e Tavares (2016) destacam que a Learning Analytics é uma das áreas que mais vêm atraindo a atenção dentro da comunidade científica que trabalha com tecnologias voltadas para a educação, pois tem o objetivo de prover formas mais eficazes aos atores que atuam na $\mathrm{EAD}$, quanto ao acompanhamento do desempenho e do engajamento dos alunos nos AVAs, antecipando a identificação de eventuais problemas. 
Com esse intuito, a Learning Analytics utiliza diferentes técnicas, entre as quais as mais comuns que são: mineração de dados educacionais, análise de redes sociais, estatística e visualização de dados (SILVA JUNIOR e OLIVEIRA, 2016). Considerando essa abordagem no âmbito da EAD, a grande quantidade de registros gerados pelos AVAs pode ser representada graficamente, de modo a possibilitar que professores, tutores e coordenadores de curso possam analisar facilmente o engajamento dos seus alunos e identificar potenciais problemas, como, por exemplo, o risco de evasão (SILVA, BRITO e MEDEIROS, 2015).

Em suma, este trabalho se situa no campo da Learning Analytics e tem como objetivo analisar a contribuição de indicadores sociais, cognitivos e comportamentais da aprendizagem dos alunos, criados com base em dados do Ava Moodle, para auxiliar professores, tutores e coordenadores de cursos on-line na identificação de alunos em risco de evasão. Para tanto, foi desenvolvido um sistema que considera os indicadores de números de acessos ao curso (disciplina), a contagem de interações nos fóruns e o desempenho dos alunos nas atividades desenvolvidas nesse AVA Moodle -, apresentando-se esses indicadores aos profissionais acima citados, na forma de relatórios e infográficos (gráficos interativos). Além disso, o sistema permite a utilização de filtros por período, a fim de facilitar a verificação e notificação da situação acima exposta - risco de evasão - aos envolvidos nos cursos a distância em execução.

\section{Metodologia}

Levando em consideração o objetivo elencado para este artigo, metodologicamente, a pesquisa teve um caráter experimental. Ao abordar esse tipo de método científico, Amaral (2011) destaca que as "metodologias experimentais são amplamente utilizadas na Ciência da Computação para avaliar novas soluções de problemas”. Similarmente ao que alvitramos nesta pesquisa, também foi proposto o desenvolvimento de um sistema computacional (plugin) em um AVA, como solução para a dificuldade de identificação, por parte de professores, tutores e coordenadores de curso, da situação acadêmica relacionada à evasão dos alunos, ao recorrerem aos relatórios e logs nativos do AVA. Utilizamos o método de pesquisa grupo focal, para avaliar se essa solução resultou em aspectos positivos e se tal ferramenta pode ser utilizada para diminuir a dificuldade acima citada, em comparação com os relatórios e logs nativos do AVA.

Em relação ao AVA, elegemos o Moodle, pelo fato de este ambiente ter seu código aberto, facilitando a condução do teste do plugin, do tipo report (relatório), que busca, em sua base de dados, as informações acerca dos alunos, das interações nos fóruns, dos acessos e das notas das atividades, tudo através de diferentes filtros. Tais dados se referem a indicadores cognitivos, sociais e comportamentais dos estudantes. Outro motivo que nos fez optar pelo Moodle foi o fato de este ser empregado no Instituto Federal da Paraíba (IFPB) e na Universidade Federal da Paraíba (UFPB), instituições vinculadas a esta pesquisa.

Vale acrescentar que grupo focal é um método de pesquisa qualitativo que coleta informações através de interações de indivíduos em entrevistas grupais planejadas (MORGAN e KRUEGER,1998). O objetivo principal dessa técnica é obter informações detalhadas sobre uma área de interesse, que pode ser um tema, sistema, produto ou serviço, a partir de um grupo de pessoas selecionadas de acordo com características afins ao assunto da pesquisa. As informações colhidas constituem subsídio para proporcionar a compreensão de percepções, atitudes e crenças dos participantes sobre o objeto de estudo. Em termos práticos, trata-se de uma discussão com um grupo de 3 a 12 pessoas, orientada/guiada por um moderador, que segue um roteiro pré-definido para que a discussão permaneça focada. A duração da sessão geralmente tem entre uma e duas horas e pode ser enriquecida com elementos, como ferramentas, protótipos ou documentos, que ajudem na análise dos objetivos da pesquisa. 
O objetivo principal do grupo focal, aplicado nesta pesquisa, foi obter a percepção dos participantes sobre as melhorias que a ferramenta aqui desenvolvida promoveu, no acompanhamento e na identificação do risco de evasão de alunos no AVA Moodle, com base nos indicadores de acesso, interações e desempenho, os quais foram escolhidos na construção da solução em forma de um plugin do tipo relatório. O grupo focal foi aplicado com professores, tutores e coordenadores de um curso superior a distância de uma instituição que oferece cursos técnicos e superiores nessa modalidade de ensino. A técnica foi enriquecida com a apresentação das telas do sistema, fazendo com que os achados no grupo focal fossem mais significativos. Para o desenvolvimento da solução proposta, este trabalho contou com as fases de concepção, análise, desenvolvimento, testes funcionais e avaliação quanto à melhoria da percepção do risco de evasão, através de um processo iterativo e incremental, em proximidade com os usuários e com a problemática investigada.

A fase de concepção envolveu três etapas, sendo a primeira voltada para o estudo do AVA Moodle e dos seus mecanismos de integração com aplicações externas. Foi verificado, então, que o Moodle se integra com novas funcionalidades através de módulos de extensão chamados de plugins e que, para instalar qualquer novo plugin no Moodle, é necessário descompactar o pacote de instalação do novo plugin interno ao diretório de instalação do Moodle, na pasta referente à categoria do tipo de funcionalidade do plugin.

A segunda etapa abrangeu o método de análise de competidores em relação às técnicas e algumas ferramentas de visualização de dados. Descobriu-se que são utilizadas técnicas específicas para exibir cada tipo de dado. Algumas tarefas de alto nível também costumam ser empregadas, adicionando funcionalidades para o usuário que utiliza a ferramenta de visualização (PLAISANT, 2005). O sistema proposto nesta pesquisa utilizou as seguintes técnicas de alto nível: visão geral, filtragem, zoom e relatório. Para a visualização de dados, foi utilizada a técnica do tipo unidimensional, com gráficos do tipo donuts e barras (CARVALHO, 2009).

A terceira etapa envolveu o levantamento e a seleção dos indicadores, criados a partir dos dados do AVA Moodle, para serem exibidos em forma de relatórios em um plugin, por meio de uma ferramenta de visualização de dados. Foi realizada uma revisão da literatura sobre o tema e definidos os indicadores para serem utilizados pelo plugin.

Na fase de análise, projetou-se um plugin do tipo report, para indicar o risco de evasão no AVA Moodle, por meio da exibição da informação de indicadores cognitivos, sociais e comportamentais dos alunos. Para tanto, foi realizada a modelagem do sistema computacional, proposta através de métodos ágeis de elicitação e especificação de requisitos, estabelecendo-se o fluxo de informações, as histórias dos usuários e os critérios de aceitação da ferramenta a ser desenvolvida.

Na fase de desenvolvimento, o plugin foi codificado, usando a linguagem de programação PHP, seguindo a linguagem nativa do AVA Moodle. Também foi empregada a linguagem de acesso ao banco de dados SQL, para realizar as consultas ao banco de dados PostgreSQL e extrair os conjuntos de dados referentes aos indicadores elencados na fase anterior deste estudo.

Já no desenvolvimento front-end, foram utilizados HTML, CSS e JavaScript, por meio do framework de desenvolvimento web Bootstrap. Os infográficos, por sua vez, foram construídos por meio do serviço Google Charts.

O Charts, do Google, é um framework gratuito que implementa protocolos de compatibilidade com várias linguagens de programação e protocolos de conexão com ferramentas variadas, permitindo a conexão, em tempo real, com bancos de dados e a escolha, entre uma variedade de gráficos, desde os simples gráficos de dispersão a mapas de árvore hierárquicos com controles interativos (GOOGLE, 2018). 
No desenvolvimento do plugin, foram empregados funções e recursos do Charts para gerar os gráficos referentes aos indicadores gerados a partir dos dados armazenados do Moodle. Em síntese, os recursos utilizados foram os seguintes: um servidor Moodle, com sistema operacional Windows 10, com Apache 2, PostgreSQL 10, PHP 7 e Moodle 3.1; Google Charts como ferramenta de visualização de dados; recursos humanos: um pesquisador, um auxiliar e quatro desenvolvedores; e gravador de voz.

O plugin desenvolvido foi instalado em um servidor de homologação do AVA Moodle, versão 3.1, com as seguintes aplicações: servidor Web Apache, versão 2; PHP, versão 7; e banco de dados PostgreSQL, na versão 10. Salas virtuais foram criadas e povoadas com usuários de teste, exercendo papéis como professores, tutores, coordenadores e alunos. Diversas simulações foram feitas com as contas de usuário dos alunos, envolvendo a realização de acessos às disciplinas, interações nos fóruns e respostas às atividades (questionários, fóruns avaliativos, tarefas etc.). Às atividades corrigidas foram atribuídas notas, pelos professores ou tutores. Em seguida, simulando-se o acesso com as contas dos professores, tutores e coordenadores, todas as funcionalidades do plugin foram testadas, uma a uma, verificando-se os infográficos e os relatórios gerados, a partir dos registros dessas atividades dos estudantes.

Na fase de avaliação do plugin desenvolvido, foi realizado um grupo focal com participação de sete pessoas: professores, tutores e coordenadores, de um curso superior a distância do Instituto Federal da Paraíba (IFPB). O grupo focal teve duração de 80 minutos e foi dividido em quatro momentos que envolveram sessões de perguntas e a apresentação das funcionalidades, dos relatórios e infográficos do referido plugin. As sessões foram gravadas em áudio os quais foram, posteriormente, transcritos. Em seguida, os dados obtidos foram codificados, considerando-se os objetivos da pesquisa.

\section{Learning Analytics}

Muitas definições podem ser atribuídas ao termo Learning Analytics. De forma mais detalhada, Gašević, Dawson e Siemens (2015) conceituam a Learning Analytics como a coleta, a análise e o relato dos dados gerados pelos alunos e seus contextos, com o objetivo de otimizar o aprendizado e o ambiente no qual este ocorre. Esse processo pode fornecer informações estratégicas sobre o que está acontecendo nos AVAs e indicar quais são os alunos que podem abandonar o curso ou aqueles que precisam de uma atenção especial para melhorar o seu desempenho dentro do ambiente virtual.

Na modalidade EAD, apoiada substancialmente pelas TICs, a Learning Analytics, entre outras possibilidades, avalia o grau de participação e as interações dos alunos, geralmente, baseando-se em métodos quantitativos, como, por exemplo: número de mensagens postadas, número de mensagens lidas, páginas visualizadas, hits, número de acessos etc. (GOMEZAGUILAR et al., 2015). Esses dados das atividades dos estudantes são coletados, registrados e armazenados pelos AVAs, em forma de logs e dados. Diante da dificuldade, porém, de interpretação desses dados coletados pelo AVA, para atingir seus objetivos, a Learning Analytics aplica, entre outras técnicas, a mineração de dados e a visualização de dados educacionais.

Na etapa de mineração dos dados, estes são processados, gerando informações sobre a aprendizagem dos alunos. Na etapa de visualização de dados, as informações são apresentadas graficamente, geralmente por meio de uma funcionalidade integrada com o AVA, classificada como Ferramenta de Learning Analytics. Essas ferramentas podem ser plugins ou aplicações para os AVAs. Os relatórios gráficos gerados por essas ferramentas são uma forma de feedback para os atores que atuam na modalidade EAD (professores, tutores, coordenadores etc.) avaliarem as suas proposições didático-pedagógicas e identificarem a necessidade de melhorias no processo de ensino-aprendizagem (DYCKHOFF et al., 2013). 


\subsection{Visualização de Dados}

A Visualização de Dados é uma área da computação gráfica e do design de interação, cujo objetivo, como qualquer outra visualização, é extrair o máximo de informação de uma grande quantidade ou volume de dados, de forma rápida, clara e precisa. Ademais, de acordo com Lyra et al. (2019, p. 197), "as visualizações têm o objetivo de representar e comunicar informações de maneira clara e eficiente, utilizando, principalmente, meios gráficos. A representação visual da informação facilita a compreensão de relações e de padrões pelo cérebro humano”.

Utilizando outras palavras, Ward, Grinstein e Keim (2015) e Coutinho et al. (2018) destacam que a visualização de dados é a área da computação gráfica que se importa com a apresentação de imagens interativas, com a finalidade de facilitar a compreensão dos dados pelos usuários e identificar suas relações. Por último, Gershon e Eick (1997) ressaltam que a visualização de dados combina aspectos da visualização científica, interface homem-máquina, mineração de dados, imagens e gráficos.

Levando em consideração os princípios inerentes às técnicas de visualização de dados, muitas ferramentas e frameworks de visualização de dados foram desenvolvidos. No plugin proposto neste trabalho, foram empregados funções e recursos do Charts, da Google, para desenhar os gráficos referentes aos indicadores, gerados a partir dos dados do banco de dados do AVA Moodle.

\subsection{Ferramentas de Learning Analytics}

As ferramentas de Learning Analytics são as aplicações desenvolvidas para propiciar Learning Analytics nos AVAs. Dyckhoff et al. (2013) ressaltam que essas ferramentas devem fornecer as funcionalidades para atingir os objetivos da Learning Analytics. Conforme esse mesmo autor, essas ferramentas devem possibilitar as ações de rastrear atividades dos alunos; capturar a interação dos alunos com recursos e com outros alunos; fornecer feedback e informações aos educadores sobre as atividades dos estudantes; destacar aspectos importantes dos dados; identificar questões problemáticas; estabelecer um sistema de alerta precoce e fornecer suporte à decisão.

Tais ferramentas baseiam-se em indicadores, criados a partir dos dados dos AVAs, para fornecer funcionalidades aos seus utilizadores, que permitam a análise visual e o reconhecimento de padrões de comportamento dos estudantes, promovendo, nas instituições, o acesso a dados reais para que professores e alunos reflitam interativamente sobre os processos de aprendizagem (NGUYEN, HUPTYCH e RIENTIES, 2018).

\subsection{Indicadores do engajamento dos alunos no AVA}

A grande quantidade de registros gerados pelos AVAs costuma ser operacionalizada na forma de indicadores. Skinner et al. (2008) explicam que o termo se refere às características que levam à construção do engajamento do estudante, indicando seu interesse, esforço, atenção, raciocínio lógico e motivação. A literatura classifica esses indicadores de engajamento em categorias. Fredricks et al. (2011) dividem os indicadores em comportamentais, cognitivos e emocionais. Já Handelsman et al. (2005), depois de dois estudos abrangentes, indicaram quatro dimensões para classificar o engajamento dos estudantes: engajamento de habilidades, engajamento emocional, engajamento de interação/participação e engajamento de desempenho.

Uma terceira abordagem foi proposta por Mazza e Dimitrova (2007), na qual os indicadores são classificados em sociais, cognitivos e comportamentais. O estudo associa a cada uma das categorias de indicadores as medidas de frequência das atividades dos alunos, fornecidas pelos 
AVAs, as quais são consideradas importantes para os professores, coordenadores e tutores acompanharem os alunos nos cursos a distância, conforme descrevemos a seguir:

- Indicadores cognitivos - relacionados ao desempenho geral dos alunos nos cursos, balizados pela sua performance nas atividades (questionários, tarefas, fóruns etc.);

- Indicadores sociais - dizem respeito às interações dos alunos nos ambientes virtuais de aprendizagem. Podem ser interações entre os estudantes, entre os estudantes e os professores e entre os estudantes e o sistema;

- Indicadores comportamentais - se referem a informações para avaliar fatores como a aprendizagem ativa, a motivação e o engajamento dos alunos (número de acessos ao curso, materiais lidos, desempenho em provas de avaliação, progresso com o cronograma do curso etc. são exemplos destas informações).

Os indicadores de engajamento cognitivo dizem respeito ao uso de estratégias e processos cognitivos, como reflexão, interpretação, síntese ou elaboração de atividades, sendo geralmente medido pelos resultados da aprendizagem, por meio das notas obtidas nas atividades, por exemplo. Os indicadores sociais ou emocionais correspondem às emoções positivas ou negativas em relação à aprendizagem, colegas de classe ou instrutores bem como interações sociais e o senso de comunidade (MEDEIROS et al., 2013b). Os indicadores comportamentais são aqueles que indicam a participação, presença, tarefas concluídas, tempo conectado ao sistema e outros comportamentos na tarefa. Henrie, Halverson e Graham (2015) afirmam que, nos contextos de aprendizagem mediada por tecnologias, o envolvimento comportamental pode, potencialmente, ser medido por indicadores gravados pelos sistemas computacionais.

Muitas ferramentas de Learning Analytics foram desenvolvidas utilizando esses três tipos de indicadores. Apresentaremos, na próxima seção, quatro ferramentas relacionadas com a nossa pesquisa, selecionadas de acordo com alguns critérios pré-estabelecidos.

\section{Trabalhos relacionados}

Muitas aplicações têm sido desenvolvidas com a finalidade de acompanhar as ações dos alunos nos AVAs, utilizando técnicas de Learning Analytics. O levantamento de trabalhos relacionados com esta pesquisa levou em consideração os seguintes critérios: o fato de o propósito do plugin estar relacionado à identificação do risco de evasão; a utilização de visualização de dados; a ferramenta pertencer ao campo de Learning Analytics; a gratuidade da ferramenta e o fato de ser desenvolvida para o AVA Moodle. A partir dessa pré-análise, concluímos que estas ferramentas de Learning Analytics são incompletas no que diz respeito à necessidade de uma análise conjunta de indicadores cognitivos, sociais e comportamentais dos alunos, ou seja, ora apresentam apenas indicadores comportamentais, ora apenas indicadores sociais e comportamentais, ora apenas indicadores sociais e cognitivos. Também não simplificam a visualização dos dados dos alunos para os profissionais que atuam na $\mathrm{EAD}$, ao agruparem muitas funcionalidades, requerendo novamente que os professores, tutores e coordenadores analisem muitas janelas/telas para obter informações significativas sobre a situação dos alunos no AVA.

\subsection{Analytics Graphs}

O plugin Analytics Graphs é uma extensão para o AVA Moodle, do tipo bloco, que considera os seguintes indicadores: notas obtidas nas atividades; quantidade de alunos que visualizou os conteúdos e que não acessou os conteúdos do curso; quantidade de alunos que enviou as atividades no prazo; quantidade de alunos que enviou as atividades fora do prazo; e quantidade de acessos ao AVA. Os gráficos utilizados são os seguintes: barras, linhas, pizzas e caixas. O plugin apresenta as seguintes funcionalidades: exibição, apresentação gráfica e resumo gráfico. 
A exibição é feita através de um gráfico de caixas das notas obtidas em todas as atividades do curso, com a utilização de conceitos estatísticos para indicar a menor nota, a maior nota, a mediana e o quartis, indicando alunos que estão com notas inferiores a $25 \%$, 50\% e $75 \%$ do total que se atribui em determinada atividade. A apresentação gráfica é realizada por meio de gráficos de barras de todos os conteúdos postados pelos professores, com as respectivas quantidades de alunos que acessaram o conteúdo em relação aos que não o visualizaram e por gráfico de barras com as quantidades de alunos, por atividade, que realizaram as submissões no prazo e fora do prazo, ou que não enviaram as atividades. O resumo gráfico das visualizações de conteúdos, da submissão de tarefas e dos acessos dos alunos no AVA se dá através de gráficos de linha e de pizza - em todos os gráficos é possível clicar na área desejada e enviar mensagens para o grupo desejado ou mensagens individuais para os alunos, conforme propõem Zielinski e Schmitt (2015).

A principal limitação dessa ferramenta, considerando o contexto desta pesquisa, é que ela não permite a visualização de um panorama mais direto e consolidado do percurso de aprendizagem dos alunos: é necessário que os utilizadores (professores, tutores e coordenadores) naveguem por seis tipos de relatórios diferentes para obter informações sobre a situação da aprendizagem de uma turma.

\subsection{Loop}

A ferramenta Loop foi desenvolvida para os AVAs Moodle e Blackboard. Os indicadores dos níveis de atividades dos alunos são divididos em três áreas principais: conteúdo, comunicação e avaliação. Na categoria conteúdo, os indicadores são o número de visualizações dos itens de conteúdo da semana ou do total do curso; o número de alunos que visualizaram os conteúdos e dos que ainda não visualizaram. Na categoria comunicação, os indicadores empregados são o número de visualizações e de postagens em cada fórum e o número de alunos que visualizaram cada fórum, por semana e no agregado total do curso. Por último, na área de avaliação, os indicadores são o número de tentativas para cada avaliação e o número de alunos por atividade, filtrados também por semana ou durante todo o curso (CORRIN et al., 2015).

As visualizações disponíveis são dispostas em um painel principal, que exibe: um gráfico de linhas com o número de visualizações semanais de conteúdos e atividades e dos eventos de aprendizagem definidos pelos professores; gráficos de linha com o número de visualizações de páginas; gráficos de linha com o número de estudantes por página, número de sessões, duração média da sessão, número de páginas visualizadas por sessão e páginas mais acessadas na semana; um histograma de frequências de acesso aos conteúdos da semana e número de páginas visualizadas ao longo do andamento do curso, exibindo o início e o fim de atividades indicadas pelo professor como evento crítico de aprendizagem; gráficos de pizzas referentes às interações dos alunos, que mostram quantas ocorreram antes ou depois do evento de aprendizagem.

A ferramenta não é indicada para verificar alunos em risco de evasão no AVA, pois está mais voltada para dar suporte aos professores na articulação das suas intenções pedagógicas e identificação de métricas relacionadas às suas intenções de design de conteúdos e atividades no AVA.

\subsection{Moodle Analytics Dashboard}

O Moodle Analytics Dashboard (MAD) é uma ferramenta de Learning Analytics desenvolvida para o AVA Moodle, na forma de uma extensão para o navegador Google Chrome. Os indicadores que a ferramenta utiliza são o número de visualizações de páginas; o número de ações distintas que um aluno realizou (um post em fórum, visualização, edição ou remoção); o número de alunos que acessaram o ambiente ou recurso; o número de dias que um aluno acessou o ambiente ou algum recurso; o número de vezes que um participante acessou o ambiente e o tempo médio da sessão e a taxa de rejeição (percentual de acessos a uma página em comparação com as demais). 
Esses dados são exibidos em um painel que disponibiliza as visualizações, o diagrama de dispersão com o tempo médio da sessão e a taxa de rejeição de professores e alunos; gráfico de linhas, com o total de páginas visualizadas por dia e por hora na semana; mapa de calor das ações dos alunos por dia da semana e hora; gráfico de linhas da quantidade de acessos por dia da semana e hora e gráfico de barras horizontais, com a opção de selecionar a quantidade de páginas visualizadas, atividades únicas, páginas únicas visualizadas, dias acessados e taxa de rejeição de todos os alunos do curso, exibidos em ordem crescente, delimitando no gráfico a média, o desvio padrão e a mediana. É possível enviar mensagem para o participante, clicando na área do gráfico.

Os gráficos foram desenvolvidos com base nas bibliotecas voltadas ao desenvolvimento Web D3.js e o Google Charts (EINHARDT, TAVARES e CECHINEL, 2016). Apesar de a ferramenta propor o monitoramento do aluno, percebemos que as verificações focam mais no contexto de curso, com a verificação de recursos acessados ou visualizados e os dias da semana/horas em que essas ações ocorreram. Ela não leva em conta o desempenho e os aspectos sociais dos alunos. Outra limitação é que funciona apenas com Google Chrome e é necessário estar logado no Moodle durante a utilização da ferramenta.

\subsection{WebMonitor}

A ferramenta WebMonitor é uma aplicação plugin, desenvolvida para o AVA Moodle, que utiliza, como indicadores, o número de arquivos postados em atividades e a quantidade de interações em fóruns ou a ausência dessas interações. Para exibir a informação visual, são utilizados gráficos do tipo donuts (rosca) e círculos, com cores variando do vermelho ao verde, para classificar os alunos conforme a sua situação acadêmica.

As funcionalidades do sistema são: opção de filtrar por grupos, exibição do percentual de estudantes por nível de participação nas tarefas obrigatórias, com os níveis Muito baixo (0-25\%), Baixo (26-50\%), Bom (51-75\%) e Excelente (76-100\%); gráficos sensíveis ao clique, habilitando enviar mensagem ao grupo de estudantes selecionado; nível de participação por aluno, exibindo a quantidade de interações de cada aluno com os módulos de atividades, com o resumo da participação do estudante na entrega das tarefas; a possibilidade de as tarefas entregues serem demarcadas na cor verde, as não entregues, mas que estão dentro do prazo, ficam na cor cinza e as que não foram entregues e estão com o prazo vencido são marcadas na cor vermelha e, por fim, a possibilidade de envio de mensagens individuais, utilizando-se o próprio módulo de mensagens do Moodle (LUCENA, SILVA e OLIVEIRA, 2015).

O plugin é considerado limitado para analisar o risco de evasão do aluno, por se basear apenas no envio de tarefas e na participação nos fóruns. Alunos podem enviar tarefas, mas não tirar boas notas ou podem interagir nos fóruns e não fazer as atividades. Além disso, o sistema classifica alunos que enviam atividades e interagem nos fóruns na cor verde, que significa excelente, mesmo quando estes estão sem acessar a disciplina há vários dias.

Nesta pesquisa é proposta uma ferramenta de Learning Analytics que busca preencher as lacunas identificadas na revisão sistemática da literatura. Para tal, são utilizados indicadores sociais, cognitivos e comportamentais dos estudantes, com a exibição de relatórios gráficos consolidados, referentes à turma como um todo e também ao aluno, individualmente. A ferramenta também exibe uma listagem com possíveis alunos em risco de evasão. Na seção 5, a ferramenta Relatório de Risco de Evasão, desenvolvida para o AVA Moodle, é apresentada.

\section{$5 \quad$ Plugin Relatório de Risco de Evasão}

Considerando os indicadores do engajamento dos alunos no AVA, segundo Mazza e Dimitrova (2007), propõe-se, com esta pesquisa, uma ferramenta de Learning Analytics que lança mão de 
técnicas de visualização de dados, para exibir dados do engajamento dos estudantes, que contemplem indicadores cognitivos, sociais e comportamentais, com o objetivo de auxiliar professores, tutores e coordenadores de cursos a distância, na identificação de estudantes em risco de evasão no AVA Moodle. Levando-se em conta a faceta quantitativa desse campo de pesquisa educacional, para atender aos aspectos cognitivos, o sistema considerou as notas obtidas pelos estudantes nas atividades, analisando a contribuição percentual que cada nota representa na pontuação total da atividade, por período. Dentro do âmbito dos aspectos sociais, o sistema utilizou o indicador de quantidade de interações dos alunos nos fóruns de discussão, entre si e com os professores e tutores, também por período. Por último, para contemplar os aspectos comportamentais, o sistema empregou o indicador quantidade de acessos à disciplina do curso, com filtros por quantidade e período.

\subsection{Definição dos Indicadores do Plugin}

\subsubsection{Indicador Cognitivo: Notas}

Estudantes engajados e motivados com o processo de aprendizagem costumam ter boas avaliações nas atividades e exames. Alqurashi (2018) confirma essa observação, ao dizer que, geralmente, os alunos que estão satisfeitos com o ambiente de aprendizagem obtêm notas mais altas, buscam melhores resultados e se saem melhor nos exames, desde o início do curso. Na EAD, os professores postam conteúdos e elaboram atividades nos AVAs, com o objetivo de avaliar a aprendizagem dos alunos. Essas atividades são avaliadas por eles ou pelos tutores, e as notas que foram atribuídas são registradas no banco de dados dos AVAs, sendo, por conseguinte, disponibilizadas para os alunos no formato de um boletim digital, muitas vezes chamado de quadro de notas.

O presente estudo utiliza essas notas como indicador, para auxiliar na identificação do risco de evasão dos estudantes. Essa solução proposta visa ao acompanhamento do progresso do aluno, ao analisar quanto a nota de desempenho em cada atividade representa percentualmente sobre o total da pontuação da atividade em um determinado período.

\subsubsection{Indicador Social: Interações nos Fóruns}

A interação desempenha um papel muito relevante tanto na educação a distância quanto na presencial. Kent, Laslo e Rafaeli (2016) defendem, no entanto, que, quando se trata da aprendizagem on-line, a interação e o engajamento cognitivo dos alunos os tornam críticos para a construção do entendimento e aquisição de novos conhecimentos. Os autores Picciano (2002), Johnson e Johnson (2010) e Medeiros et al. (2013a) mencionam a relação entre a presença social dos alunos nos ambientes de aprendizagem on-line com os resultados de aprendizagem como indicadores de engajamento e desempenho cognitivo.

Considerando que alunos motivados dificilmente vão abandonar seus cursos, a não ser por motivos pessoais de força maior, Picciano (2002) afirma que alunos e professores relatam maior satisfação em cursos on-line, dependendo da qualidade e da quantidade de interações nos ambientes virtuais de aprendizagem. Priorizando, portanto, essa abordagem que leva em consideração a quantidade de interações como um fator de permanência dos alunos nos cursos, entendemos que a quantidade de postagens de alunos em fóruns de discussão constitui um indicador do engajamento dos estudantes nos cursos a distância.

\subsubsection{Indicador Comportamental: acessos ao curso}

$\mathrm{O}$ acesso se refere à frequência com que alunos acessam as plataformas ou ambientes de aprendizagem, os cursos, as atividades e os conteúdos disponibilizados pelos professores. Conforme atesta um estudo realizado por Benta, Bologa e Dzitac (2014), os alunos que obtiveram 
notas mais altas acessaram com mais frequência a plataforma, enquanto os alunos com notas mais baixas assim não o fizeram.

Esses acessos constituem um bom indicador do comportamento dos alunos nos AVAs, porém, por si só, não são suficientes para monitorar a aprendizagem dos estudantes. Lykourentzou et al. (2009) explicam que, embora o aluno acesse com frequência o ambiente de aprendizagem on-line, ele pode obter notas baixas e, eventualmente, abandonar o curso. Diante disso, a combinação de indicadores de acessos, notas e interações permitirá aos professores, tutores e coordenadores de curso traçarem um perfil mais detalhado e completo dos alunos e, então, identificar padrões de comportamento que indicam o engajamento e aqueles que estão com dificuldades, podendo estes últimos abandonar o curso em que estão matriculados.

\subsection{Cenário de Uso do Plugin}

Para atender aos objetivos da pesquisa, foi desenvolvido um plugin para o Moodle, do tipo report (relatório), que busca, na base de dados desse AVA, os dados dos alunos referentes às interações nos fóruns, aos acessos e às notas das atividades, por período, e os exibe para tutores, coordenadores e professores, de acordo com os filtros aplicados, com a intenção de identificar alunos em risco de evasão. O fluxo de informações do plugin inicia-se com os alunos acessando a plataforma Moodle e realizando suas atividades acadêmicas; o Moodle, então, registra, em sua base de dados, os dados referentes às atividades dos alunos; os professores, tutores e coordenadores acessam o relatório e selecionam filtros para acessos, interações e percentual de notas de atividades; o sistema recupera e processa os dados dos acessos, interações e notas dos alunos, a partir da base de dados do Moodle e, a partir dos dados processados, o sistema gera o relatório com as informações dos alunos exibidas através da ferramenta de visualização de dados. Para auxiliar nosso entendimento, a Figura 1 exibe a arquitetura do sistema.

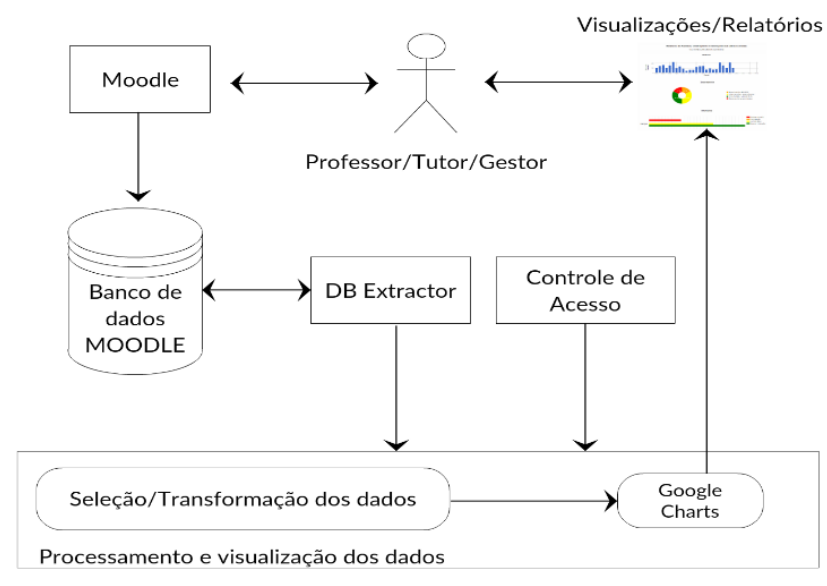

Figura 1: Arquitetura de funcionamento do plugin.

Conforme descreve a Figura 1, o sistema é composto por três partes principais: a partição DB Extractor, a partição Controle de Acesso e a partição Processamento e Visualização de Dados. $D B$ Extractor é a parte do sistema responsável por coletar, no banco de dados do Moodle, os dados referentes às ações de visualização dos alunos em um curso e as datas nas quais os acessos ocorreram; as postagens dos alunos nos fóruns de discussão bem como as datas nas quais ocorreram e as notas das atividades dos alunos e também as datas em que foram postadas. A partição Controle de Acesso é responsável por limitar a exibição e a utilização do plugin apenas aos usuários do Moodle que atuam como Professor, Tutor e Coordenador de Curso. Basicamente, o Moodle funciona baseado em contextos, permissões e papéis. Então, a partição de Controle de Acesso define que, em um contexto de um curso, apenas os papéis de professor, tutor e 
coordenador têm permissão para visualizar o relatório de risco na área de Administração do curso e utilizar as suas funcionalidades.

A partição Processamento e Visualização de Dados corresponde ao tratamento e às formas de exibição dos dados extraídos do banco de dados. Os dados das interações, acessos e desempenho dos alunos são processados para incluir informações adicionais e executar alguns cálculos, de acordo com os parâmetros definidos na concepção do sistema e com os filtros fornecidos pelos usuários do plugin. Os filtros são a quantidade de acessos, o percentual de desempenho e as datas inicial e final para exibição dos relatórios. Em seguida, esses dados são convertidos para estruturas gráficas, no formato de listagens e gráficos interativos. As visualizações gráficas foram implementadas utilizando-se o Google Charts.

\subsection{Visualizações do Plugin}

O plugin Relatório de Risco de Evasão, como o próprio nome já diz, é um relatório feito para funcionar dentro da hierarquia de um curso no Moodle, que representa uma sala de aula dentro do AVA. Desta forma, o acesso ao plugin estará disponível para os professores, tutores e coordenadores - os utilizadores do sistema - no bloco de Administração do curso, na opção Relatórios, com o nome "Relatório de Risco de Evasão". Quando se clicar no nome do plugin, será carregada sua interface inicial, conforme apresentado na Figura 2.
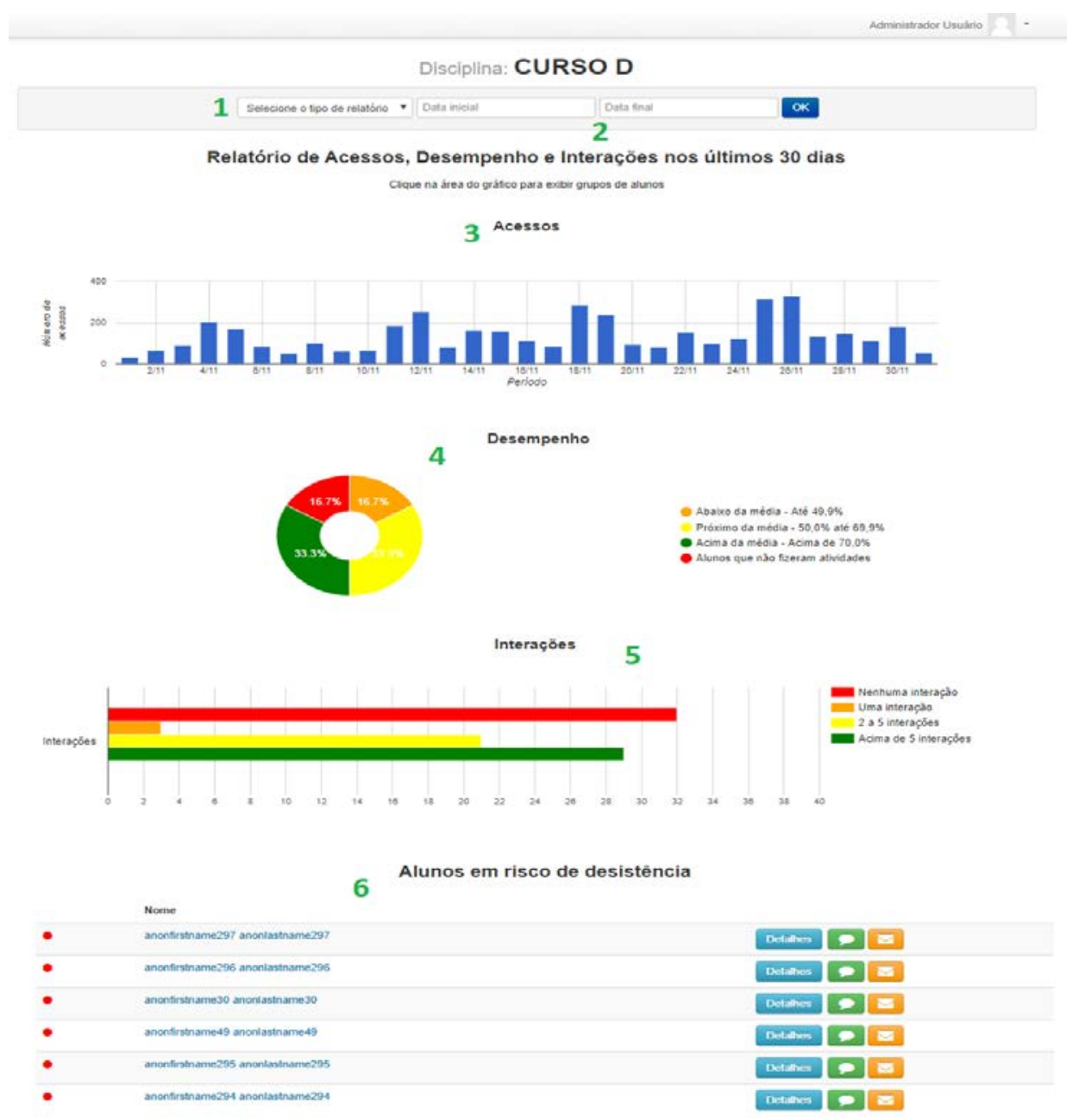

Figura 2: Tela inicial do plugin Relatório de Risco de Evasão.

A tela principal do sistema exibe um painel que contém o nome da disciplina, um seletor do tipo de relatório (1), filtros de data para os relatórios (2) e os infográficos do sistema: um gráfico 
de quantidade de acessos (3), um gráfico de desempenho (4) e um gráfico de interações dos alunos nos fóruns da disciplina (5), referentes aos últimos 30 dias. Por último, apresenta uma lista de alunos em risco potencial de abandono da disciplina, intitulada "Alunos em risco de desistência" (6).

Todos os gráficos são interativos e as áreas dos gráficos de acessos, desempenho e interações são sensíveis ao clique. Ao se clicar em qualquer área de qualquer um dos três gráficos, aparecerá a listagem de alunos correspondente à situação selecionada no gráfico e, também, o botão "Mais +” para verificar detalhes do grupo selecionado. O usuário poderá notificar um aluno, enviandolhe mensagens pelo Moodle ou pelo e-mail. O infográfico de acessos, mostrado na Figura 3, é um gráfico de barras verticais que apresenta, no eixo vertical, a quantidade de acessos feitos por alunos distintos e, no eixo horizontal, a data dos acessos, com os alunos correspondentes, referente aos últimos 30 dias.

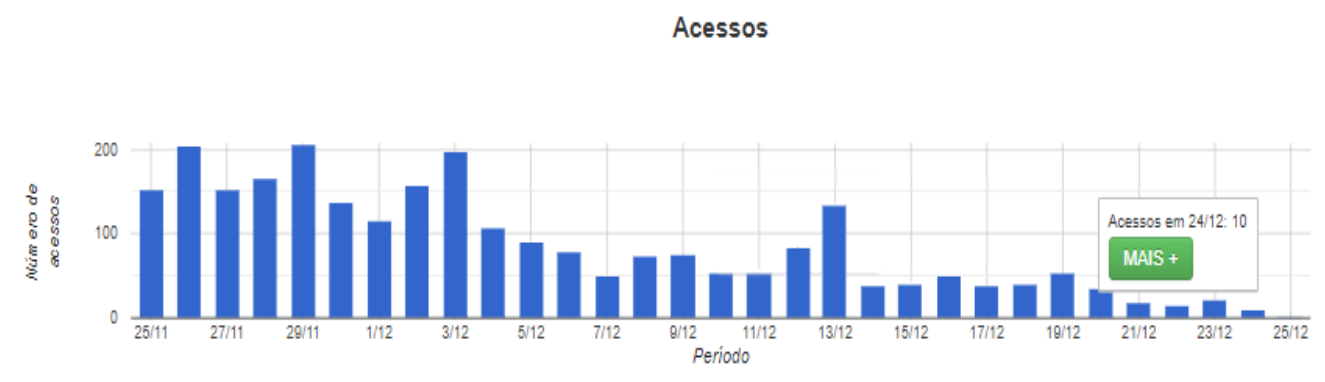

Figura 3: Gráfico de acessos.

Para obter a quantidade de acessos, em qualquer dia do intervalo, basta que se clique na área do gráfico correspondente ao dia selecionado. Por exemplo, ao selecionarmos a barra do gráfico correspondente ao dia 24/12, conforme evidencia a Figura 3, veremos que, nesse dia, foram realizados 10 acessos à disciplina, por 10 alunos distintos. Já, para saber quais alunos fizeram os acessos nesse dia, basta clicarmos no botão “Mais +”. O resultado é exibido na Figura 4.

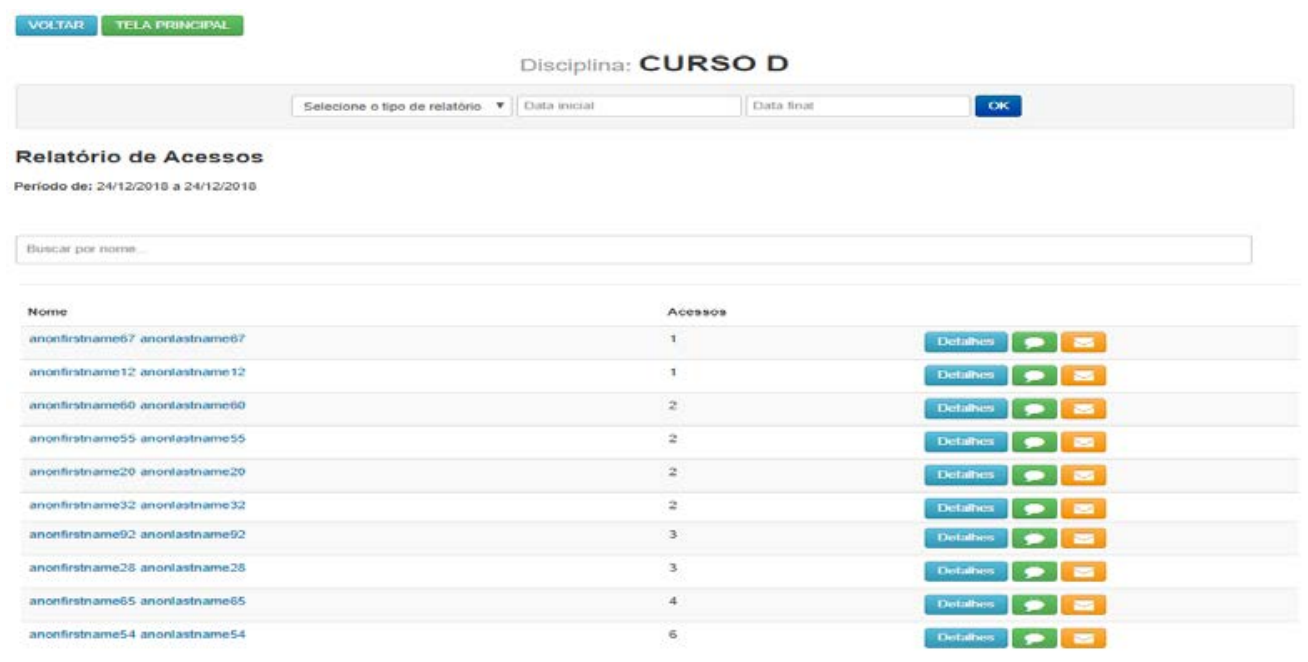

Figura 4: Detalhamento do gráfico de acessos.

Quando o usuário clicar no botão "Mais +”, referente ao dia 24/12, por exemplo, será carregado o relatório de acessos daquele dia, com os alunos que acessaram a disciplina e a quantidade de acessos feitos por cada um deles, nesse dia. O usuário poderá buscar pelo nome de um aluno específico na opção "Buscar por nome” ou verificar na listagem um aluno específico e clicar no botão "Detalhes”, para analisar o relatório consolidado desse aluno; se desejar, poderá 
enviar-lhe mensagens pelo Moodle ou e-mail, clicando nos botões verdes ou laranja, respectivamente.

Continuando, na Figura 5, é mostrado o infográfico de desempenho. Trata-se de uma exibição visual do tipo donuts, que apresenta, em "fatias", o desempenho dos alunos, de acordo com o seu rendimento nas atividades, este dividido em quatro grupos: acima da média, abaixo da média, próximo da média e alunos que não fizeram as atividades. Alunos com desempenho acima de $70,0 \%$ serão representados pela cor verde; alunos com rendimento entre 50,0\% e 69,9\% pertencerão ao grupo de cor amarela, no gráfico; alunos com rendimento abaixo de 49,9\% são exibidos na cor laranja e os alunos que não fizeram as atividades, o grupo mais crítico, são apresentados na cor vermelha. Esses intervalos foram estabelecidos com base na média de aprovação adotada nos cursos das instituições de ensino técnico e superior (IFPB/UFPB) envolvidas com esta pesquisa.

Desempenho

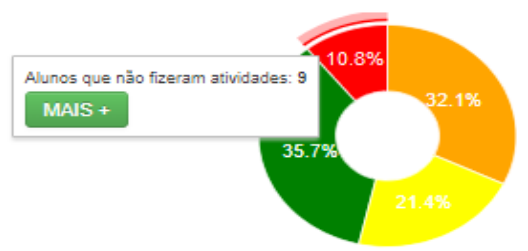

Abaixo da média - Até $49,9 \%$

Próximo da média - $50,0 \%$ até $69,9 \%$

- Acima da média - Acima de $70,0 \%$

- Alunos que não fizeram atividades

Figura 5: Gráfico de desempenho.

Assim como no infográfico de acessos, para saber a quantidade de alunos em cada situação, basta clicar na área do gráfico desejada. No exemplo da Figura 5, ao clicar na região do gráfico referente aos alunos que não fizeram as atividades, por exemplo, veremos que nove alunos, o que corresponde a $10,8 \%$ da turma, não postaram as atividades propostas na disciplina, no intervalo referente aos últimos 30 dias. Se o usuário desejar saber quais alunos estão em cada situação, basta clicar no botão "Mais +". O resultado dessa ação é exibido na Figura 6.

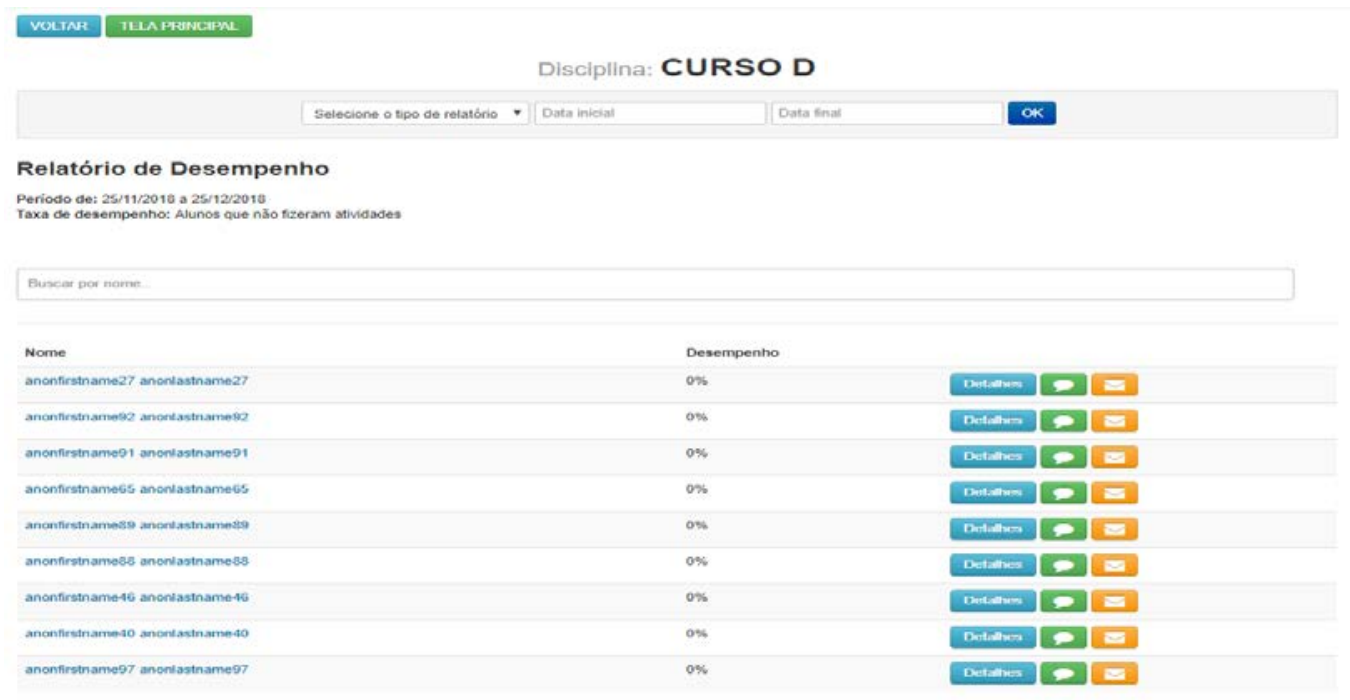

Figura 6: Detalhamento do gráfico de desempenho.

O usuário poderá verificar, então, o grupo de alunos e as suas médias percentuais correspondentes, relativas às notas nas atividades dos últimos 30 dias. No exemplo da Figura 6, como os alunos não postaram as atividades, o rendimento será $0.0 \%$. A partir dessa tela, o usuário poderá, então, enviar uma mensagem, clicar para exibir detalhes do estudante ou buscar pelo nome de um aluno específico e verificar o relatório consolidado individual com notas, acessos e 
interações. O usuário pode, ainda, enviar uma mensagem personalizada através do próprio Moodle ou por e-mail. O último infográfico é o de interações nos fóruns, conforme apresenta a Figura 7.

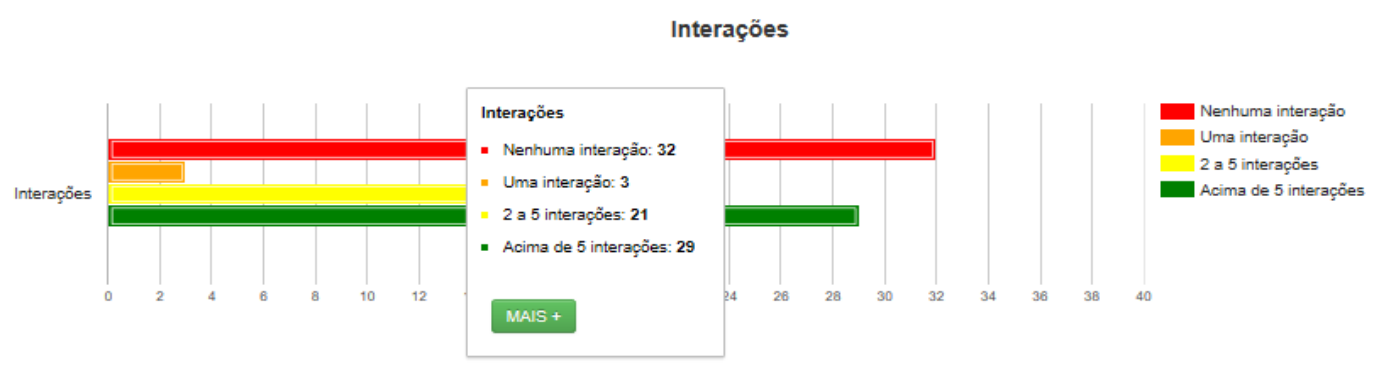

Figura 7: Gráfico de interações dos alunos nos fóruns.

Trata-se de um gráfico de barras horizontais que indicam a quantidade de interações nos fóruns nos últimos 30 dias. Alunos com mais de cinco interações são destacados na cor verde; alunos com número de postagens entre duas e cinco interações são exibidos na cor amarela; com uma interação, na cor laranja, e alunos que não fizeram nenhuma postagem nesse período, o grupo mais crítico, são identificados com cor vermelha. Para saber a quantidade de alunos que interagiu nos fóruns, basta clicar na região do gráfico. No caso das interações nos fóruns, o plugin apresentará um resumo quantitativo referente a todos os grupos de quantidade de interações, conforme mostra a Figura 7. Ao se clicar no botão “Mais +", é carregada a lista dos alunos com a quantidade de interações, apresentando os alunos que menos interagiram ou não interagiram em nenhum momento, no topo da lista, seguidos dos que mais interagiram, no fim da lista, em ordem crescente, como é visto na Figura 8.

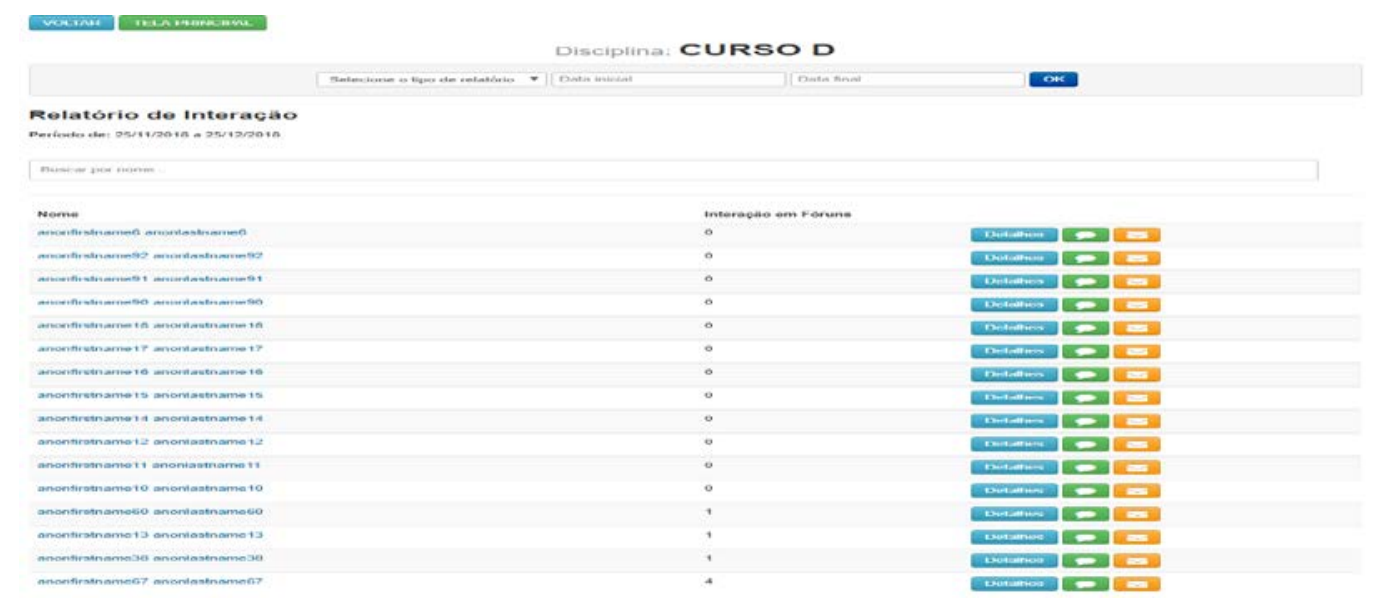

Figura 8: Detalhamento do gráfico de interações nos fóruns.

A última exibição do painel é a listagem dos alunos em risco de evasão, segundo mostra a Figura 9. Essa listagem é composta pela intersecção dos indicadores de grupos críticos, que são os alunos com nenhuma interação nos fóruns, notas abaixo de 60,0\% e com menos de quatro acessos nos últimos 30 dias. Esses alunos foram classificados como alunos em potencial risco de evasão e foram evidenciados no relatório para professores, tutores e coordenadores visualizarem um grupo crítico de forma mais rápida e em destaque, sem a necessidade de navegar nos relatórios de cada indicador. Esses parâmetros foram escolhidos com base na nota mínima que é essencial para a aprovação, considerando as instituições de ensino brasileiras, assim como a frequência mínima e a colaboração no Moodle em uma semana. 


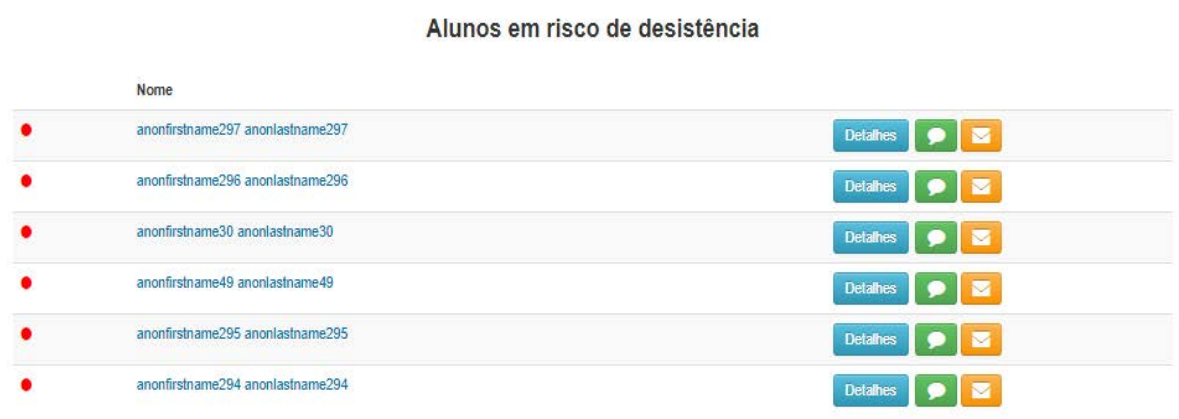

Figura 9: Listagem dos alunos em risco de evasão.

Ainda nesta tela e assim como nas demais telas da ferramenta, ao clicar no botão "Detalhes”, ao lado do nome do aluno, o professor/tutor/coordenador poderá verificar a informação individual e consolidada do estudante selecionado referente à sua quantidade de acessos, ao seu percentual de desempenho nas atividades e à sua quantidade de interações nos fóruns. No exemplo da Figura 10, o aluno não realizou nenhum acesso à disciplina, não fez nenhuma postagem nos fóruns e o desempenho dele é 2,13\%. O professor poderá enviar mensagem para o estudante, utilizando o próprio módulo de mensagens do Moodle, clicando no botão verde com o símbolo do balão do diálogo ou enviar mensagem pelo cliente de e-mail do computador, clicando no símbolo do envelope na cor laranja.

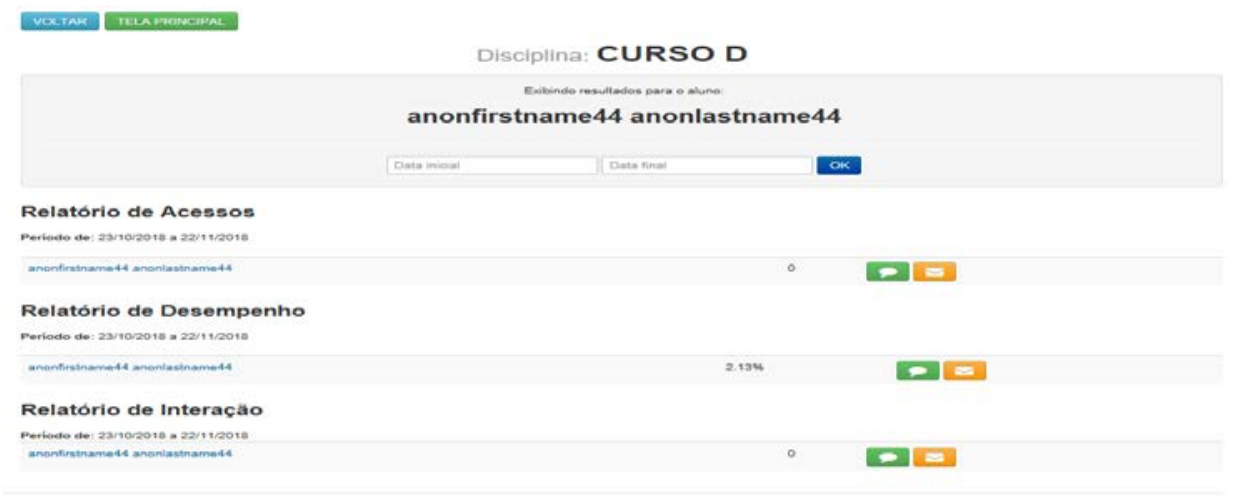

Figura 10: Relatório individual e consolidado do aluno.

\subsection{Relatórios do Plugin}

O plugin possui três relatórios, um para cada um dos indicadores: acessos, desempenho e interações, apresentados na Figura 11. Esses relatórios foram elaborados para exibir tão somente as informações de acessos, desempenho e interações, com filtros e com a possibilidade de serem definidos períodos de tempo menores ou maiores do que os 30 dias dos infográficos do painel principal da ferramenta. O formato e a apresentação das listagens, resultantes da aplicação dos filtros, são os mesmos que são exibidos quando o usuário clica na região de qualquer infográfico, conforme abordamos na seção anterior. 


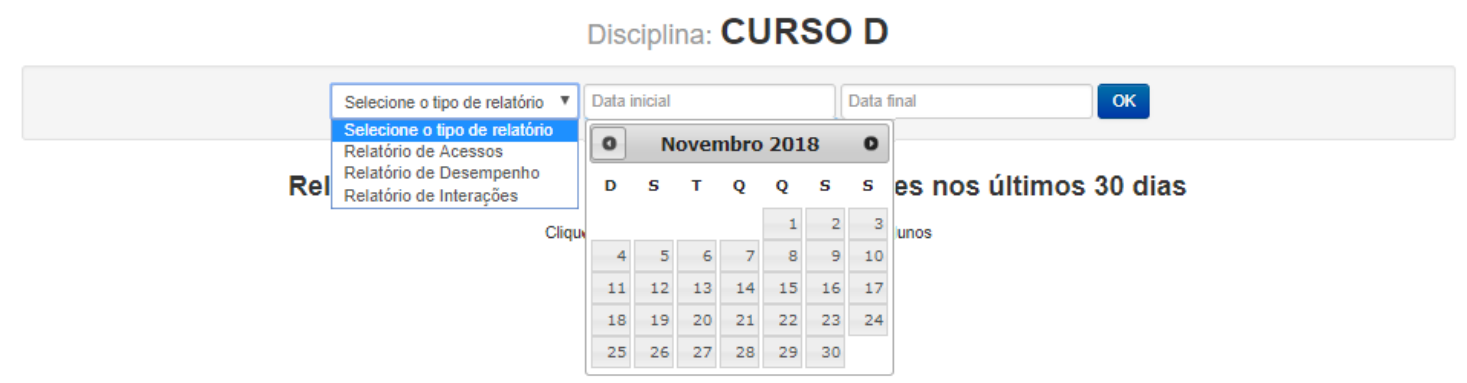

Figura 11: Seleção do tipo de relatório.

O primeiro relatório, mostrado na Figura 12 a seguir, é o de acessos. Por meio desse relatório, professores, tutores e coordenadores poderão selecionar alunos de acordo com filtros de quantidades de acessos, em um período de tempo determinado pela data inicial e final.

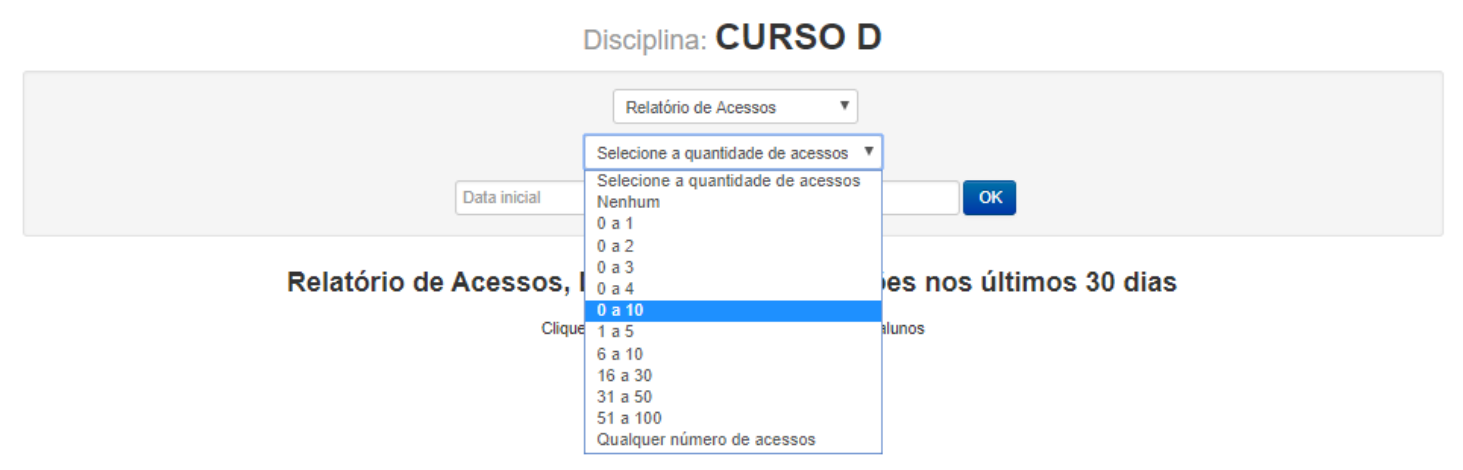

Figura 12: Filtros do Relatório de acessos.

Depois que a quantidade de acessos e a data inicial e a final, nas quais se deseja visualizar os acessos, são escolhidas, será carregada a listagem de alunos de acordo com os filtros definidos. Mais uma vez, será exibido o botão "Detalhes” para checar a situação consolidada de acessos, desempenho, interações e acessos do aluno selecionado na lista, assim como é carregado o grupo de alunos, quando o usuário clica em qualquer região dos infográficos. Essa opção de filtros também está disponível no relatório de desempenho, porém, dessa vez, baseada na média percentual obtida nas atividades, no período definido pelo utilizador do sistema. Isso é exemplificado na Figura 13.

\section{Disciplina: CURSO D}

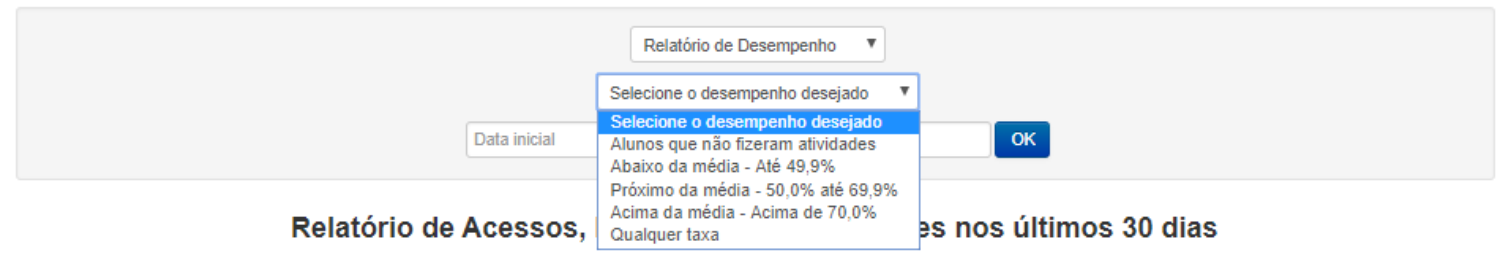

Figura 13: Filtros do Relatório de desempenho.

O usuário poderá escolher exibir o relatório de alunos de acordo com os seguintes filtros: Alunos que não fizeram atividades; Alunos abaixo da média - até 49,9\%; Alunos próximos da média - 50,0\% a 69,9\%; Alunos acima da média - acima de 70,0\% ou, ainda, qualquer taxa de desempenho, no período de tempo que o usuário definir. Ao se selecionar qualquer um dos filtros, será carregada a lista de alunos que se encaixa nos filtros definidos. Também será exibido o botão "Detalhes” para cada aluno, permitindo checar a situação consolidada de acessos, desempenho, interações e acessos de um aluno da lista, assim como ocorre quando o usuário clica na região dos 
gráficos para obter o grupo de alunos em cada situação. Os mesmos filtros por quantidades são exibidos no gráfico de interações, mas referentes às postagens. Para facilitar o uso do plugin, um manual da ferramenta foi elaborado, explicando detalhadamente o sistema. Todas as suas funcionalidades foram apresentadas para um grupo de professores, tutores e coordenadores de curso, com experiência no acompanhamento dos alunos no AVA Moodle e foi realizado um grupo focal para avaliação do plugin proposto.

\subsection{Avaliação e Análise do Plugin}

O grupo focal teve como objetivo avaliar, junto a professores, tutores e coordenadores de curso, se a ferramenta desenvolvida nesse trabalho melhora sua percepção sobre a identificação de alunos que estão em risco de evasão, facilitando e simplificando o trabalho de acompanhamento dos alunos, em comparação com os relatórios e logs nativos do Moodle.

O grupo focal foi realizado com professores, tutores e coordenadores de cursos da modalidade a distância do Instituto Federal da Paraíba - IFPB, experientes no acompanhamento de alunos no AVA Moodle. Foram sete participantes: dois com experiência como tutores, dois coordenadores de curso e três professores. Esses profissionais atuam nos cursos técnicos profissionalizantes e superiores nas áreas de Informática e Computação bem como nos cursos superiores de Licenciatura em Letras e Administração, com experiência média de quatro anos de atuação na educação a distância.

O grupo focal foi dividido em quatro momentos: no primeiro, foi discutida a importância do acompanhamento dos alunos nos AVAs; no segundo momento, discutiram-se as dificuldades de se acompanharem acessos, interações nos fóruns e o desempenho dos alunos no AVA; no terceiro momento, apresentou-se o plugin desenvolvido e sugeriu-se que os participantes interagissem com ele; no quarto momento, discorreu-se sobre o suporte oferecido pelo plugin à percepção da melhoria do acompanhamento dos alunos no AVA para a identificação daqueles em risco de abandono dos cursos. Nesse momento, também se buscou levantar sugestões de melhorias para a ferramenta desenvolvida. O grupo focal teve duração de 80 minutos, durante os quais foram respondidas seis questões, facilitadas pelo pesquisador e por um auxiliar. O primeiro, o segundo e o quarto momento foram compostos por duas questões cada um. O terceiro momento, no qual foi feita a apresentação e o uso do plugin, não contemplou questões.

Os dados obtidos na condução do grupo focal, diretamente relacionados aos objetivos da pesquisa, foram analisados qualitativamente considerando três nós (códigos): (i) Importância do acompanhamento dos alunos nos AVAs sob a perspectiva da evasão; (ii) Dificuldades em acompanhar os indicadores sociais, cognitivos e comportamentais dos estudantes com o suporte ferramental nativo do Moodle; e (iii) Percepção dos professores e tutores quanto ao suporte oferecido pelo plugin para o acompanhamento dos indicadores e risco de evasão dos estudantes. As sessões de grupo focal foram transcritas e codificadas com o auxílio do software de análise de dados qualitativos NVivo 11 para posterior análise.

Essas três categorias, nas quais foram agrupados e analisados os dados, seguiram uma lógica de encadeamento das respostas no que tange à perspectiva de acompanhamento dos indicadores e risco de evasão dos estudantes sem e com o suporte ferramental. Os participantes levantaram a importância do acompanhamento dos estudantes no AVA, seguida das dificuldades que enfrentam para realizar esse trabalho com os relatórios e ferramentas nativas dos AVAs, culminando na apresentação e discussão sobre o plugin. Após isso, elencaram como a solução proposta pode resolver ou diminuir essas dificuldades, trazendo melhorias no acompanhamento dos estudantes e, consequentemente, ajudando na identificação de estudantes em risco de evasão. Nas seções 5.5.1, 5.5.2 e 5.5.3 são apresentadas as análises qualitativas dos três códigos, com base nos dados coletados nos grupos focais. 


\subsubsection{Importância do acompanhamento dos alunos nos AVAs sob a perspectiva da evasão}

Os participantes foram questionados sobre qual a importância do acompanhamento dos alunos nos ambientes virtuais de aprendizagem, de modo a investigar a relevância que os professores, tutores e coordenadores atribuem a esse acompanhamento, já que se trata de uma modalidade de educação sem a convivência presencial em sala de aula física, mas fortemente amparada pelas tecnologias, conforme trechos das respostas apresentados na Tabela 1.

Tabela 1: Trechos do grupo focal sobre a importância do acompanhamento dos alunos no AVA.

\begin{tabular}{|c|c|}
\hline Fonte & Trechos \\
\hline Professor 1 & $\begin{array}{l}\text { "A importância é fundamental [...], porque é só assim, vamos dizer que, a essa relação } \\
\text { de escola, de sala aula, ela acontece mesmo!” }\end{array}$ \\
\hline Professor 2 & $\begin{array}{l}\text { "O acompanhamento do aluno é essencial para manter o aluno, conquistar o aluno, } \\
\text { fazê-lo se sentir valorizado e criar até um vínculo afetivo, do jeito que a gente } \\
\text { consegue fazer isso com o presencial. Se a gente tem esse acompanhamento constante, } \\
\text { ele se sente observado, valorizado e a gente tem uma resposta melhor." }\end{array}$ \\
\hline Tutor 1 & $\begin{array}{l}\text { "Eu percebi que o aluno não estava vendo os conteúdos e comecei a mandar } \\
\text { mensagens... para ver se provocava mais interesse neles para estar assistindo." }\end{array}$ \\
\hline Coordenador 1 & $\begin{array}{l}\text { “... a importância de se fazer esse acompanhamento é de evitar a evasão e gerir a } \\
\text { permanência. [...] O que é preciso fazer é uma gestão da permanência e uma forma de } \\
\text { fazer a gestão da permanência é esse acompanhamento da participação na plataforma, } \\
\text { um tratamento personalizado do aluno.” }\end{array}$ \\
\hline Coordenador 2 & $\begin{array}{l}\text { "A gente não conseguia ter } 100 \% \text {, aí, do que a gente espera, mas quando a gente } \\
\text { transforma esses dados em uma estratégia mesmo, de dialogar, de chamar a atenção } \\
\text { para determinados pontos, eu acho que o aluno... ele começa a ser guiado." }\end{array}$ \\
\hline Professor 3 & $\begin{array}{l}\text { “... porque não é só a questão do desempenho e da evasão, mas também da gente } \\
\text { conhecer o nosso aluno, traçar perfis de turmas.” }\end{array}$ \\
\hline
\end{tabular}

Os professores, tutores e coordenadores destacaram a importância do acompanhamento dos alunos na perspectiva de se evitar a evasão, através da aplicação de estratégias que visem à permanência desses alunos, provenientes de origens muito heterogêneas, e também diante do impacto da adaptação necessária à modalidade de educação a distância. Além disso, os participantes consideram relevante fazer o acompanhamento para ver o andamento da aprendizagem dos alunos e atender às suas demandas e necessidades de aprendizagem para aumentar seu interesse e a sua satisfação com o curso.

Os participantes da pesquisa levantaram, também, a necessidade do acompanhamento para se dar um feedback mais eficiente e imediato aos alunos, a fim de dirimir as barreiras da distância e aproximar mais o ambiente virtual do ambiente vivenciado na sala de aula presencial. Ademais, acrescentaram que é vital o acompanhamento do aluno para traçar um perfil de turmas, a fim de dar um tratamento mais personalizado para cada um deles. Um dos motivos da evasão é a sensação de isolamento com a qual alguns cursistas se deparam ao ingressarem na modalidade a distância. Desta forma, fazer o acompanhamento para identificar esse perfil de estudantes e aqueles que, por outras razões, estejam desmotivados a continuar, é um fator que pode efetivar sua permanência nos cursos.

Quando se questionou sobre como os participantes deste estudo avaliam o impacto do acompanhamento dos estudantes no AVA, pretendia-se relacionar sua percepção quanto a esse acompanhamento com o fenômeno da evasão e obter respostas mais específicas, tendo em vista estar se tratando de um problema assaz preocupante para a EAD - a evasão. Trechos das respostas são relatados na Tabela 2 . 
Tabela 2: Trechos do grupo focal sobre a importância do acompanhamento na perspectiva da evasão.

\begin{tabular}{|c|l|}
\hline Fonte & \multicolumn{1}{c|}{ Trechos } \\
\hline Professor 3 & $\begin{array}{l}\text { "Eu acho que é a possibilidade de você poder intervir antes que a evasão de fato ocorra } \\
{[\ldots], \text { na primeira semana essa intervenção é fundamental! Gestão da permanência!” }}\end{array}$ \\
\hline Professor 2 & $\begin{array}{l}\text { "Se a gente não ficar perto deles (alunos), eles saem com facilidade, porque eles não } \\
\text { se sentem parte. Até identificar-se como alunos do IFPB, para eles é difícil.” }\end{array}$ \\
\hline Coordenador 1 & “Gestão da permanência!” \\
\hline
\end{tabular}

Percebeu-se um consenso dos participantes em relação à possibilidade de se acompanharem os alunos para evitar a evasão antes que ela ocorra e que o acompanhamento é a principal forma de se gerir a permanência do aluno. As respostas de todos os participantes corroboraram que o acompanhamento do aluno tem como razão principal a necessidade de se evitar a evasão nos cursos em que atuam. Foi notado que todos têm essa preocupação, principalmente nas primeiras semanas do curso. Há a prática de se verificar os alunos que nunca acessaram e, então, entrar em contato com esses alunos, principalmente enviando mensagens através da própria plataforma Moodle.

Foi relatado o caso de uma aluna que tinha a intenção de desistir do curso nos primeiros dias, e isso foi constatado pelo professor, ao verificar os acessos dos alunos na plataforma Moodle. Após uma mensagem do professor, questionando razões para a ausência da aluna nas atividades, ela se sentiu valorizada pela instituição e concluiu o curso. Foi constatado também que os participantes concordam que o acompanhamento permite identificar estudantes que estão em risco de abandonar os cursos e a tomada de medidas de retenção desses alunos - embora não seja eficaz em todos os casos, costuma surtir efeitos positivos, em algumas situações, e todos consideraram isso importante para o aluno, para o professor e para a instituição.

\subsubsection{Dificuldades em acompanhar os indicadores sociais, cognitivos e comportamentais dos estudantes com o suporte ferramental nativo do Moodle}

Objetivou-se analisar quais estratégias os participantes utilizam no AVA Moodle para realizar o acompanhamento dos alunos e quais relatórios, indicadores e logs eles têm a prática de verificar para averiguar a situação acadêmica desses estudantes. É fundamental reforçar que todos os professores, tutores e coordenadores que participaram do grupo focal possuíam uma vasta experiência com a plataforma Moodle e com a prática docente on-line, de maneira que foi possível extrair as principais limitações dos relatórios do AVA para acompanhamento dos indicadores dos estudantes, em um cenário usual de turmas grandes e com inúmeras atribuições ao professor.

Tabela 3: Trechos do grupo focal sobre como é feito o acompanhamento dos alunos no Moodle.

\begin{tabular}{|c|l|}
\hline Fonte & \multicolumn{1}{c|}{ Trechos } \\
\hline Coordenador 2 & $\begin{array}{l}\text { "A primeira coisa que eu faço é verificar os alunos que nunca acessaram. Tanto eu, } \\
\text { quanto o tutor, como professor em relação aos meus colegas que trabalham comigo, } \\
\text { geralmente eu oriento que nos primeiros dias é um período de adaptação, então os } \\
\text { alunos entram, alguns não entram, mas podem entrar (no AVA) se a gente } \\
\text { realmente entrar em contato.” }\end{array}$ \\
\hline Professor 1 & $\begin{array}{l}\text { "Eu me utilizo dessa mesma estratégia, em relação aos participantes: ver quem acessa, } \\
\text { quem nunca acessa e envio mensagens.” }\end{array}$ \\
\hline Coordenador 1 & $\begin{array}{l}\text { "Quando eu passei as atribuições para os tutores fazerem o acompanhamento dos } \\
\text { alunos, cada um na sua disciplina, eu orientei para que eles fizessem esse controle } \\
\text { semanalmente, justamente para que aqueles nunca acessaram... porque se em uma }\end{array}$ \\
\hline
\end{tabular}




\begin{tabular}{|c|c|}
\hline & $\begin{array}{l}\text { semana se identificam esses que nunca acessaram, pode ser mais fácil de resgatar } \\
\text { do que se passar um mês e continuar nunca tendo acesso e aí pode ser que, nesse caso, } \\
\text { quem nunca acessou possa vir a acessar e participar daquela atividade.” }\end{array}$ \\
\hline Professor 2 & $\begin{array}{l}\text { “... eu só olhava os que, a partir de uma semana, começavam a não visualizar aí é } \\
\text { que me preocupava, porque oito dias, quinze dias sem entrar... aí esses realmente eu } \\
\text { vou atrás e já consegui umas respostas boas.” }\end{array}$ \\
\hline Professor 1 & $\begin{array}{l}\text { “Quando eu vejo que não há dúvidas no fórum de dúvidas, tem alguma coisa errada. } \\
\text { [...] porque é impossível uma aula inteira, duas semanas e não tem nenhuma dúvida em } \\
\text { relação aquilo, né? [...] Eu olho os fóruns quase todos os dias, já é rotina.” }\end{array}$ \\
\hline Tutor 2 & $\begin{array}{l}\text { Geralmente nos fóruns avaliativos, eu sempre peço que eles comentem a postagem do } \\
\text { outro colega. [...] Então eu percebo que isso dá uma interação maior, dá uma vivacidade } \\
\text { no fórum,’. }\end{array}$ \\
\hline Professor 3 & $\begin{array}{l}\text { "Eu faço uma verificação básica, que é olhar o boletim. [...] É no relatório do usuário, } \\
\text { que aí você vê eles (alunos) na lista." }\end{array}$ \\
\hline Coordenador 2 & $\begin{array}{l}\text { "No quadro de notas, gera o relatório do usuário que aí você vê o desempenho } \\
\text { dele." }\end{array}$ \\
\hline Professor 3 & “Também vou no relatório (de notas) do usuário.” \\
\hline
\end{tabular}

Observou-se que a maioria dos participantes costuma verificar, dentro de suas disciplinas, primeiramente alunos que nunca acessaram e a frequência do acesso à disciplina. Constatou-se, ainda, que os acessos à disciplina e aos conteúdos são o principal indicador utilizado pelos participantes para monitorar a atividade do aluno no AVA, conforme podemos observar em trechos como: "A primeira coisa que eu faço é verificar os alunos que nunca acessaram" e "Eu me utilizo dessa mesma estratégia, em relação aos participantes: ver quem acessa, quem nunca acessa e envio mensagens". Os coordenadores de curso orientam os tutores a irem ao relatório de participantes do Moodle, a fim de verificar o último acesso e quem nunca acessou a disciplina e, em seguida, entrar em contato com esses alunos, por mensagem do Moodle ou por telefone.

Também frisaram que a participação dos alunos nos fóruns de discussão, principalmente os de dúvidas, que são semanais, é avaliada como indicador importante do engajamento do aluno, consoante evidenciado nos trechos: "Eu olho os fóruns quase todos os dias, já é rotina" e "eu sempre peço que eles comentem a postagem do outro colega". Notou-se que o fórum é uma ferramenta colaborativa muito utilizada e valorizada pelos professores. Além dos fóruns de dúvidas, é prática dos professores criarem fóruns avaliativos, nos quais os alunos são avaliados pelas interações que fazem com as postagens de outros colegas. Eles acreditam que o fórum, dentro do Moodle, é a ferramenta que mais aproxima os alunos e essa interação promove a permanência do aluno.

Para verificar o rendimento dos alunos, os professores e tutores costumam verificar o relatório de notas ou "boletim" de cada aluno, segundo podemos observar nos trechos: "Eu faço uma verificação básica, que é olhar o boletim" e "No quadro de notas, gera o relatório do usuário que aí você vê o desempenho dele”. Nesse relatório é apresentado um quadro com todas as notas em todas as atividades que foram desenvolvidas pelo professor. Notou-se, porém, que essa verificação é realizada principalmente no final do semestre para obter a lista de alunos que foram aprovados por média e os que necessitam fazer a prova final.

Quando os facilitadores do grupo focal questionaram mais diretamente os participantes quanto à utilização dos relatórios e logs do Moodle e quais as dificuldades específicas eles têm enfrentado para buscar informações relativas aos acessos, às notas e às interações dos alunos nos fóruns, algumas observações relevantes foram discutidas. A Tabela 4 apresenta alguns trechos das falas dos participantes relacionados a essa questão. 
Tabela 4: Trechos do grupo focal sobre as dificuldades em acompanhar os alunos no Moodle.

\begin{tabular}{|c|c|}
\hline Fonte & Trechos \\
\hline Professor 3 & $\begin{array}{l}\text { "Eu sei que existem os gráficos de rendimento no Moodle e que eles são importantes, } \\
\text { mas eu ainda tenho certa dificuldade de trabalhar com aqueles gráficos. Eu acesso, } \\
\text { olho, a gente entra lá, tem os gráficos, mas eu ainda tenho uma certa dificuldade. [...] } \\
\text { você fica com uma sensação de incompetência total. Aí eu não sei se existe um } \\
\text { recurso para a gente selecionar a média dos alunos frequentantes e participantes para } \\
\text { poder acessar esses gráficos.” }\end{array}$ \\
\hline Coordenador 1 & $\begin{array}{l}\text { “[...] foi estabelecido um tipo de relatório a partir desse relatório (de notas) do } \\
\text { Moodle, que é um pouco bruto, as informações são brutas, os dados [...], porque se } \\
\text { for fazer individualmente esse acompanhamento, fica muito, muito trabalhoso... } \\
\text { Então, com as informações do Moodle, que podem ir para uma planilha, fazemos um } \\
\text { tratamento no Excel”. }\end{array}$ \\
\hline Professor 2 & $\begin{array}{l}\text { "A outra dificuldade é essa: eu acho aqueles gráficos de rendimento por atividade } \\
\text { maravilhosos, mas eu não consigo separar os alunos ativos dos alunos inativos, isso } \\
\text { gera resultados falseados. [...] No fórum, quando a gente tem muito aluno, é difícil } \\
\text { você rolar a barra. [...] não tem filtro ali nos relatórios. Aí, eu tenho que ficar vendo } \\
\text { assim: quem fez e quem não fez.” }\end{array}$ \\
\hline Tutor 1 & $\begin{array}{l}\text { "Poderia ser mais intuitivo. [...] eu tive bastante dificuldade em saber as atividades } \\
\text { que aqueles determinados alunos fizeram ou não, lá no quadro de notas, que é muito } \\
\text { complicado. [...] tem a dificuldade incrível de identificar qual a atividade que o aluno } \\
\text { fez para você poder fazer a parte do contato. [...] Se a gente não consegue interpretar } \\
\text { o que está sendo mostrado, então vai ter essa dificuldade." }\end{array}$ \\
\hline Professor 1 & $\begin{array}{l}\text { “A visualização do quadro de notas é mesmo complicada. É confusa. Eu acho que } \\
\text { seria muito interessante que a gente pudesse, no quadro de notas, visualizar essa nota } \\
\text { individual, os acessos, o rendimento da turma... tudo em um quadro só. [...] O } \\
\text { problema está na visualização.” }\end{array}$ \\
\hline
\end{tabular}

Os relatórios do Moodle são tidos como pouco intuitivos, às vezes muito extensos, estáticos, sem a possibilidade do uso de muitos filtros e de difícil interpretação. Alguns professores se sentem confusos em relação às informações dos relatórios e, às vezes, precisam recorrer a ferramentas externas para tratar os dados e obter informações mais claras e precisas sobre os alunos. Além disso, consideram os gráficos complexos e moroso o trabalho de verificar acessos, interações e notas, individualmente, por relatório e por aluno.

As respostas dos participantes do grupo focal evidenciaram não só as dificuldades que eles encontram ao utilizar os relatórios e logs do Moodle para fazer o acompanhamento dos alunos, mas também a necessidade que eles têm da utilização de filtros, de visualização e de relatórios mais diretos e precisos, com as informações de notas, acessos e interações dos alunos mais consolidadas, em um único quadro. Consoante essa necessidade dos atores que atuam nos ambientes virtuais de aprendizagem, foi desenvolvido um plugin para o Moodle e a ferramenta foi apresentada com todas as suas funcionalidades para os membros do grupo focal.

\subsubsection{Percepção dos professores e tutores quanto ao suporte oferecido pelo Plugin para o acompanhamento dos indicadores e risco de evasão dos estudantes}

Para discutir e analisar a percepção dos professores e tutores quanto ao suporte oferecido pelo plugin para o acompanhamento dos indicadores e risco de evasão dos estudantes, os facilitadores do grupo focal apresentaram o plugin Relatório de Risco de Evasão em um ambiente Moodle de homologação, onde todas as funcionalidades e relatórios foram minuciosamente detalhados em um cenário real de uso. Abordaram-se os infográficos de acesso, desempenho e interação. A partir daí, foi explicado como clicar nas áreas de cada gráfico para se ter a exibição dos grupos de alunos, acessar informações individuais dos alunos, enviar mensagens, verificar o relatório consolidado individual do estudante e também verificar individualmente os relatórios de acessos, interações e 
desempenho, definindo filtros por datas e faixas baseadas nas quantidades de acessos, percentual de desempenho e interações.

Após o momento de apresentação do plugin pelo pesquisador, foi sugerido que os participantes interagissem com o plugin. Dos sete participantes do grupo focal, quatro interagiram - dois de forma individual e dois em uma mesma instância. As tarefas realizadas pelos participantes, durante a interação, foram a geração do relatório de risco de evasão e a aplicação de alguns filtros dos indicadores de acesso, de desempenho e de interação. Durante as interações, solicitou-se que os participantes relatassem a execução das tarefas em voz alta, através da técnica de Think Aloud, de modo que esses relatos fossem considerados na etapa de análise qualitativa dos dados juntamente com as entrevistas do grupo focal.

Após a apresentação detalhada do plugin, o pesquisador questionou os professores, tutores e coordenadores se a ferramenta melhoraria a percepção sobre a identificação de alunos que estão em risco de evasão e se seria útil, neste sentido, para o trabalho que fazem do acompanhamento dos alunos no Moodle, com base nas interações, acessos e desempenho. A Tabela 5 apresenta alguns trechos das falas dos participantes relacionados a essa questão.

Tabela 5: Trechos do grupo focal sobre como o plugin melhora a percepção sobre a identificação de alunos em risco de evasão.

\begin{tabular}{|c|c|}
\hline Fonte & Trechos \\
\hline Tutor 1 & $\begin{array}{l}\text { "Essa ferramenta que você criou, ela favorece uma resposta mais direta, mais rápida e o } \\
\text { contato mais direto com o aluno. Você já está vendo a situação daquele aluno e aí você já } \\
\text { vai diretamente ali para enviar e-mail e mensagem. [...] A gente precisa ter essas } \\
\text { ferramentas para ajudar e otimizar o nosso tempo e também pensar o acompanhamento desse } \\
\text { aluno, no caso, vê logo esses que nunca acessaram." }\end{array}$ \\
\hline Professor 3 & $\begin{array}{l}\text { "Eu, particularmente, gostei dos filtros que foram criados, porque, como eu estava falando, eu } \\
\text { sei que existem os gráficos, pois já tentei usar, mas, para mim, eles criaram distorções porque } \\
\text { não faziam uma secção adequada para as informações que eu precisava. E aqui me parece que } \\
\text { os filtros estão mais objetivos e mais visuais. A seleção de cores... então eu já sei logo } \\
\text { tantos por cento nunca acessou. Essa linguagem visual eu acho que facilita demais o nosso } \\
\text { trabalho." }\end{array}$ \\
\hline Tutor 1 & $\begin{array}{l}\text { "Hoje em dia a informação está aí, em todo local, e a gente se acostumou a ter essa informação } \\
\text { de forma fácil, sem perder tempo. A gente quer olhar para uma coisa e já filtrar, pegar as } \\
\text { informações... sem precisar pensar, ali, direto! Pá-Pum! E pelo que a gente viu aqui, está dessa } \\
\text { forma: mais fácil, dá para a gente acompanhar o aluno de forma diária e de forma mais } \\
\text { efetiva. Eu gostei muito.” }\end{array}$ \\
\hline Tutor 2 & $\begin{array}{l}\text { "Quando você vai para um recurso desse, você está ali pontuando, ou seja, isolando aquela } \\
\text { situação e está situando melhor o aluno naquele seu caso...até fazendo uma autorreflexão } \\
\text { sobre a sua participação mesmo!” }\end{array}$ \\
\hline Professor 1 & $\begin{array}{l}\text { "Eu acho que esse recurso que você apresenta para o professor, abre uma possibilidade muito } \\
\text { grande de intervenção e essa intervenção, no sentido de resgatar esse aluno que nunca } \\
\text { acessou, que está indo embora, que se evadiu... que está abandonando o curso, de recuperar } \\
\text { esse aluno que está tendo um rendimento insuficiente, porque a gente vai olhar dia a dia, semana } \\
\text { por semana. Então, vai possibilitar fazer esse acompanhamento de forma mais efetiva e } \\
\text { mais objetiva e muito mais prática.” }\end{array}$ \\
\hline Coordenador 1 & $\begin{array}{l}\text { "A vantagem, do ponto de vista administrativo, que eu acho que é parte relacionada aos } \\
\text { professores, porque o pedagógico já foi bem discutido aqui, é de permitir com que nós nos } \\
\text { antecipemos ao não acesso do aluno, diante das informações que são passadas em relação a } \\
\text { vários aspectos." }\end{array}$ \\
\hline Coordenador 2 & $\begin{array}{l}\text { "Essa ferramenta vai nos ajudar bastante. [...] a apresentação da ferramenta, dialoga com o que } \\
\text { eu falei agora pouco de que a gente tem muitos recursos no Moodle, mas às vezes é difícil } \\
\text { dar esse tratamento, digo, o professor poder filtrar os dados e atuar. E os critérios que } \\
\text { você elencou, dos acessos, das interações e notas, são primordiais. Eu acho que você fez } \\
\text { uma seleção muito interessante, muito importante em relação à participação do aluno. A } \\
\text { questão do layout, do design dessa ferramenta, das cores... ficou muito mais fluído fazer o } \\
\text { acompanhamento na ferramenta, por meio desse plugin e imediatamente atuar, intervir... já }\end{array}$ \\
\hline
\end{tabular}




\begin{tabular}{|c|l|}
\hline & $\begin{array}{l}\text { que eu posso entrar no perfil do aluno, verificar detalhes, enviar mensagens... Então eu } \\
\text { acho que a gente só tem a ganhar com essa ferramenta." }\end{array}$ \\
\hline Professor 2 & $\begin{array}{l}\text { "Quando a gente tem um instrumento desse, que vai diretamente, identifica o problema e tem } \\
\text { o canal para a gente falar com o aluno imediatamente, então fica bem específica a natureza } \\
\text { do contato. Com essa ferramenta, você acaba deixando a coisa mais clara, não só para nós, mas } \\
\text { principalmente para o aluno." }\end{array}$ \\
\hline
\end{tabular}

As respostas dos participantes foram todas positivas sobre as melhorias que a ferramenta pode trazer para o trabalho de acompanhamento que desempenham no Moodle. Em comparação com os relatórios e logs nativos desse AVA, a ferramenta retira distorções, por apresentar filtros adequados e permite identificar de forma mais clara, objetiva e fácil a situação acadêmica dos estudantes, baseada nos acessos, nas interações e nas notas, possibilitando intervir na situação pedagógica dos alunos, buscando resgatar aqueles que nunca acessaram e tentando recuperar os que estão tendo um rendimento insuficiente.

A ferramenta correspondeu às necessidades elencadas pelos participantes do grupo focal, com relação a filtros objetivos e visuais, gráficos mais claros; foi, portanto, avaliada como um instrumento que otimizará o trabalho de acompanhamento que fazem no Moodle, tornando-o mais efetivo, com frequências diária e semanal, segundo podemos observar nos trechos: "E pelo que a gente viu aqui, está dessa forma: mais fácil, dá para a gente acompanhar o aluno de forma diária e de forma mais efetiva" e "...ficou muito mais fluído fazer o acompanhamento na ferramenta”. Outro ponto levantado, como sendo forte na ferramenta é a funcionalidade de se verificar a situação acadêmica do aluno e poder enviar mensagens mais diretas imediatamente, favorecendo uma resposta mais rápida para aqueles identificados como em risco de evasão, com o auxílio do plugin. Os trechos que evidenciam essas melhorias são os seguintes: “...ela favorece uma resposta mais direta, mais rápida e o contato mais direto com o aluno"; " os filtros estão mais objetivos e mais visuais. A seleção de cores...então eu já sei logo tantos por cento nunca acessou" e "Você já está vendo a situação daquele aluno e aí você já vai diretamente ali para enviar e-mail e mensagem".

Os indicadores de acessos, desempenho e interações, que são utilizados no plugin, para auxiliar a identificação de alunos em risco de evasão, foram avaliados como estratégicos, primordiais e muito importantes para avaliar a participação dos estudantes no AVA, conforme podemos comprovar nos trechos: "os critérios que você elencou, dos acessos, das interações e notas, são primordiais" e "Eu acho que você fez uma seleção muito interessante, muito importante em relação à participação do aluno". Através do relatório consolidado desses indicadores, em um só quadro, os participantes assinalaram que é possível antecipar e intervir nas situações de alunos sem acesso, por meio do envio de mensagem ou outras formas de contato.

O layout dos gráficos e o design do plugin foram avaliados como muito apropriados. Mais de uma vez, foi argumentado que a informação visual possibilita clareza na identificação da situação do aluno e as funcionalidades apresentadas pelo plugin tornam mais fluido o trabalho de acompanhar os estudantes e, imediatamente, atuar e intervir, nos casos identificados como risco de abandono. Uma nuvem de palavras foi concebida para refletir esse momento da avaliação do plugin, conforme mostra a Figura 14. 


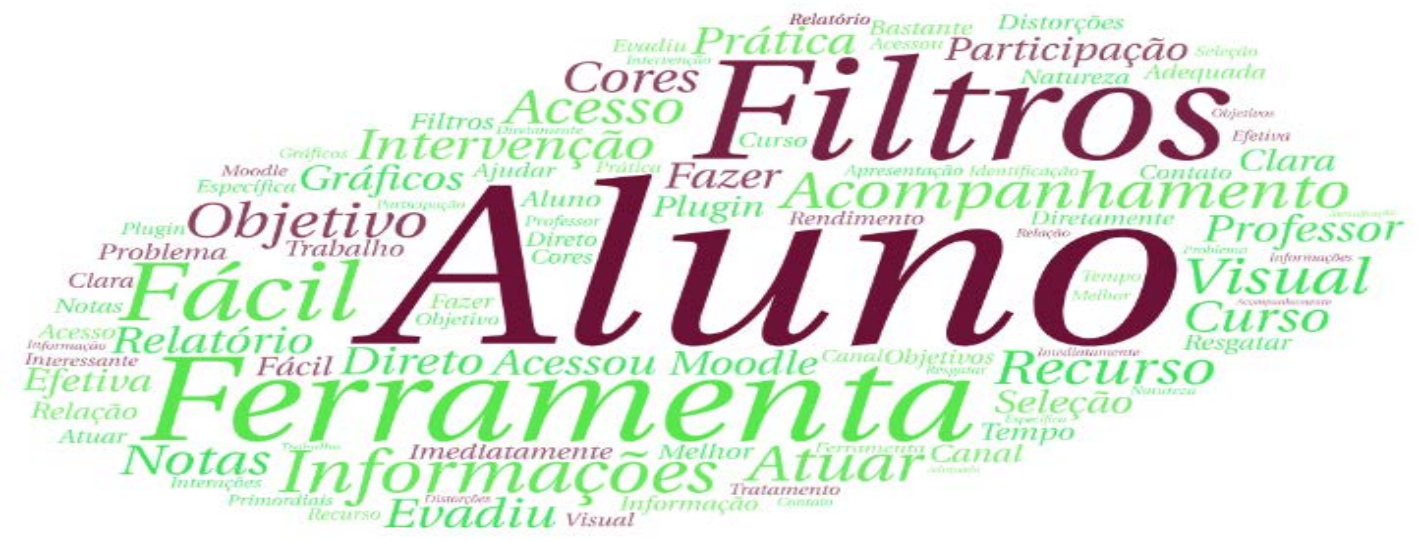

Figura 14: Nuvem de palavras do Momento 4 do grupo focal.

A nuvem de palavras da Figura 14 mostrou que a funcionalidade do plugin que mais foi apreciada pelos professores, tutores e coordenadores que participaram do grupo focal, foram os filtros, pois são muito escassos no Moodle. Eles acreditam que, dessa forma, a ferramenta possibilita fazer o acompanhamento do aluno de forma mais fácil, objetiva e direta, permitindo a intervenção e o resgate daquele aluno que se evadiu. Por último, o grupo focal identificou algumas limitações no plugin, apresentadas pelos participantes: (i) não possibilitar a exportação dos relatórios para outros formatos como planilhas e pdf; (ii) não possuir um filtro por polo, pois os tutores atuam em polos específicos dentro de uma mesma turma; e (iii) servir apenas para os alunos, pois os coordenadores e professores também sentem a necessidade de acompanhar os acessos dos tutores.

\section{Conclusões}

O artigo objetivou analisar a contribuição de indicadores sociais, cognitivos e comportamentais da aprendizagem remota dos alunos. Para tanto, nos baseamos em estudos da literatura para eleger aspectos de aprendizagem pertinentes ao Ambiente Virtual de Aprendizagem Moodle. Para atender aos aspectos cognitivos, consideramos as notas obtidas pelos estudantes nas atividades, analisando a contribuição percentual que cada nota representa na pontuação total da atividade. Visando abranger os aspectos sociais, consideramos a quantidade de interações dos alunos nos fóruns de discussão. E, para contemplar os aspectos comportamentais, empregamos o indicador quantidade de acessos à disciplina do curso, com filtros por quantidade e período.

O grupo focal, realizado com professores, tutores e coordenadores com experiência no acompanhamento dos alunos no AVA Moodle, nos levou a conclusões muito relevantes para essa pesquisa. Buscou-se, através do Grupo Focal, obter a percepção dos participantes sobre as melhorias que a ferramenta desenvolvida na pesquisa promoveu no acompanhamento e na identificação do risco de evasão de alunos no AVA Moodle. A ferramenta de Learning Analytics Relatório de Risco de Evasão ofereceu a professores, tutores e coordenadores de curso mecanismos que promoveram maior acuidade com os alunos que estão em risco de evasão, com base nos indicadores de acessos, interações e desempenho. Os participantes reconheceram esse suporte no plugin mencionado, considerando-o como uma ferramenta bastante funcional, em comparação com as logs e relatórios nativos do Moodle; avaliaram-no positivamente, com filtros muito úteis, indicadores estratégicos, com informação visual que facilita e otimiza o seu trabalho de acompanhamento dos alunos no AVA, além de fornecer um canal de comunicação que permite, de forma mais direcionada e imediata, notificar os alunos que não acessaram o AVA ou mesmo o fazendo, apresentando baixo rendimento. 
Concluiu-se também, a partir das respostas do Momento II do grupo focal, que os acessos à disciplina, as interações nos fóruns e também as notas constituem a tríade de indicadores principais que professores, tutores e coordenadores dos cursos superiores a distância do IFPB costumam utilizar para realizar o acompanhamento dos alunos no AVA Moodle. Ao realizar, porém, este trabalho, utilizando as ferramentas nativas do Moodle, muitas dificuldades são encontradas, como, por exemplo: a ausência de filtros mais específicos, relatórios pouco intuitivos, estáticos e pouca informação visual.

Diante disso, enfatizamos que o desenvolvimento de uma ferramenta Learning Analytics sempre deve priorizar dados estratégicos dos alunos e que as notas, interações e acessos, com filtros e visualizações adequados, constituem indicadores simples, que podem ser utilizados para auxiliar professores, tutores e coordenadores na identificação do risco de evasão de alunos no AVA, especialmente se utilizados em conjunto. Também é importante que a ferramenta permita a notificação de estudantes considerados no grupo de risco, na forma de um canal mais direto e imediato.

Os professores, tutores e coordenadores que participaram do grupo focal indicaram algumas limitações no sistema que podem ser exploradas melhor em trabalhos futuros. As melhorias são: incorporar à ferramenta um filtro por grupos, já que atuam atendendo a alunos que são divididos em grupos, vinculados aos polos de apoio presencial de outros Campi do IFPB; a viabilização da funcionalidade de exportar as listagens dos relatórios de risco, acesso, desempenho e interações para o formato de planilhas e arquivos pdf. É também uma proposta de trabalho futuro que a ferramenta seja mais dinâmica e permita que os próprios professores, tutores e coordenadores customizem os parâmetros para indicar o risco de evasão dos estudantes no Moodle. Nessa perspectiva, eles poderiam informar ao sistema o número de acessos, a quantidade de interações e também um percentual de notas que são, para eles, parâmetros para indicar o abandono dos cursos, de acordo com a realidade de cada turma e as suas experiências nos cursos.

As etapas já concluídas nesta pesquisa, desde a escolha do referencial teórico e dos indicadores sociais, cognitivos e comportamentais, perpassando pela construção do suporte ferramental através do plugin Relatório de Risco de Evasão e sua integração no AVA Moodle, até a avaliação do plugin pelos professores, tutores e coordenadores quanto à percepção do risco de evasão dos estudantes em cursos a distância, são significativas e ao mesmo tempo encorajadoras para uma investigação mais aprofundada de quanto esse suporte impacta positivamente na melhora desses indicadores e na diminuição da evasão.

Como trabalho futuro, portanto, foi planejado um experimento de campo em duas disciplinas regulares a distância de um curso superior do IFPB, com dois professores distintos, no período de dois semestres. No semestre 2020.1 o professor de uma das disciplinas teria como suporte o plugin Relatório de Risco de Evasão integrado ao Moodle, enquanto o outro professor utilizaria o Moodle convencional, alternando o suporte no semestre 2020.2. A hipótese é que, nas disciplinas cujos professores contarão com o suporte do plugin e foram orientados a intervir junto aos alunos regularmente com base nos infográficos, os indicadores de acessos, interações e notas sejam melhorados bem como a taxa de evasão seja menor que nas disciplinas cujos professores não receberam o suporte da ferramenta. As análises serão realizadas a partir dos dados coletados do AVA Moodle através de análises estatísticas descritivas, em dois momentos, após o primeiro semestre do experimento e após o segundo, considerando os indicadores acumulados.

\section{Referências:}

Alqurashi, E. (2018). Predicting student satisfaction and perceived learning within online learning environments. Distance Education, 1-16. doi: 10.1080/01587919.2018.1553562 [GS Search] 
Amaral, J. N. (2011). About computing science research methodology. Disponível em: https://webdocs.cs.ualberta.ca/ c603/readings/research-methods.pdf. [GS Search]

Benta, D., Bologa, G., \& Dzitac, I. (2014). E-learning platforms in higher education. Case study. Procedia Computer Science, 31, 1170-1176. doi: 10.1016/j.procs.2014.05.373 [GS Search]

Carvalho, E. S., \& Marcos, A. F. (2009). Visualização de informação. Centro de Computação Gráfica (CCG). Disponível em: http://repositorium.sdum.uminho.pt/handle/1822/8863. [GS Search]

Cohen, A. (2017). Analysis of student activity in web-supported courses as a tool for predicting dropout. Educational Technology Research and Development, 65(5), 1285-1304. doi: 10.1007/s11423-017-9524-3 [GS Search]

Corrin, L., Kennedy, G., De Barba, P., Bakharia, A., Lockyer, L., Gasevic, D., \& Copeland, S. (2015). Loop: A learning analytics tool to provide teachers with useful data visualisations. Disponível em: https://www.researchonline.mq.edu.au/vital/access/services/Download/mq: 43896/SOURCE1. [GS Search]

Costa, R. L. D., \& Santos, J. C. D. (2017). Dropout in distance technical courses. Educar em Revista, (66), 241-256.doi: 10.1590/0104-4060.50700 [GS Search]

Coutinho, E., Bezerra, J., Bezerra, C. I. M., \& Moreira, L. O. (2018, October). Uma Análise da Evasão em Cursos de Graduação Apoiado por Métricas e Visualização de Dados. In: Anais do Workshop de Informática na Escola (Vol. 24, No. 1, p. 31). doi: 10.5753/cbie.wie.2018.31 [GS Search]

Dobashi, K. (2016). Development and trial of excel macros for time series cross section monitoring of student engagement: analyzing students' page views of course materials. Procedia Computer Science, 96, 1086-1095. doi: 10.1016/j.procs.2016.08.133 [GS Search]

Dyckhoff, A. L., Zielke, D., Bültmann, M., Chatti, M. A., \& Schroeder, U. (2012). Design and implementation of a learning analytics toolkit for teachers. Journal of Educational Technology \& Society, 15(3). Disponível em: https://www.researchgate.net/publication/ 266872275_Design_and_Implementation_of_a_Learning_Analytics_Toolkit_for_Teachers [GS Search]

Einhardt, L., Tavares, T. A., \& Cechinel, C. (2016, October). Moodle analytics dashboard: A learning analytics tool to visualize users interactions in Moodle. In Learning Objects and Technology (LACLO), Latin American Conference on (pp. 1-6). IEEE. doi: 10.1109/LACLO.2016.7751805 [GS Search]

Fredricks, J., McColskey, W., Meli, J., Mordica, J., Montrosse, B., \& Mooney, K. (2011). Measuring Student Engagement in Upper Elementary through High School: A Description of 21 Instruments. Issues \& Answers. REL 2011-No. 098. Regional Educational Laboratory Southeast. Disponível em: https://eric.ed.gov/?id=ED514996 [GS Search]

Gašević, D., Dawson, S., \& Siemens, G. (2015). Let's not forget: Learning analytics are about learning. TechTrends, 59(1), 64-71. doi: 10.1007/s11528-014-0822-x [GS Search]

Gómez-Aguilar, D. A., Hernández-García, Á., García-Peñalvo, F. J., \& Therón, R. (2015). Tap into visual analysis of customization of grouping of activities in eLearning. Computers in Human Behavior, 47, 60-67. doi:10.1016/j.chb.2014.11.001 [GS Search]

Google. Charts. Disponível em: https://developers.google.com/chart/. Acesso em: jan. 2018.

Handelsman, M. M., Briggs, W. L., Sullivan, N., \& Towler, A. (2005). A measure of college student course engagement. The Journal of Educational Research, 98(3), 184-192. doi: 10.3200/JOER.98.3.184-192 [GS Search] 
Henrie, C. R., Halverson, L. R., \& Graham, C. R. (2015). Measuring student engagement in technology-mediated learning: A review. Computers \& Education, 90, 36-53. doi: 10.1016/j.compedu.2015.09.005 [GS Search]

Johnson, G. M., \& Johnson, J. A. (2010). Dimensions of online behavior: implications for engineering E-learning. In Technological developments in education and automation (pp. 6166). Springer, Dordrecht. doi: 10.1007/978-90-481-3656-8_13 [GS Search]

Kent, C., Laslo, E., \& Rafaeli, S. (2016). Interactivity in online discussions and learning outcomes. Computers \& Education, 97, 116-128. doi: 10.1016/j.compedu.2016.03.002 [GS Search]

Kostopoulos, G., Kotsiantis, S., \& Pintelas, P. (2015, October). Estimating student dropout in distance higher education using semi-supervised techniques. In: Proceedings of the 19th Panhellenic Conference on Informatics (pp. 38-43). ACM. doi: $\underline{10.1145 / 2801948.2802013}$ [GS Search]

Lucena, K. T., Silva, J., \& Oliveira, E. (2015, October). WebMonitor: uma ferramenta para monitoramento e acompanhamento de cursos em um AVA. In: Brazilian Symposium on Computers in Education (Simpósio Brasileiro de Informática na Educação-SBIE) (Vol. 26, No. 1, p. 249). doi: 10.5753/cbie.sbie.2015.249 [GS Search]

Lykourentzou, I., Giannoukos, I., Nikolopoulos, V., Mpardis, G., \& Loumos, V. (2009). Dropout prediction in e-learning courses through the combination of machine learning techniques. Computers \& Education, 53(3), 950-965. doi: 10.1016/j.compedu.2009.05.010 [GS Search]

Lyra, K., Reis, R., Cruz, W. \& Isotani, S. (2019). Um framework de classificação de complexidade para infográficos. Revista Brasileira de Informática na Educação, V(27), N.1, doi: http://dx.doi.org/10.5753/rbie.2019.27.01.196 [GS Search]

Mazza, R., \& Dimitrova, V. (2007). CourseVis: A graphical student monitoring tool for supporting instructors in web-based distance courses. International Journal of HumanComputer Studies, 65(2), 125-139. doi:10.1016/j.ijhcs.2006.08.008 [GS Search]

Medeiros, F., Gomes, A. S., Amorim, R., \& Medeiros, G. (2013, July). Architecture for Social Interactions Monitoring in Collaborative Learning Environments as a Support for the Teacher's Awareness. In: Advanced Learning Technologies (ICALT), 2013 IEEE 13th International Conference on (pp. 123-127). IEEE. doi: 10.1109/ICALT.2013.41 [GS Search]

Medeiros, F., Gomes, A., Amorim, R., \& Medeiros, G (2013). Redesigning collaboration tools to enhance social presence in online learning environments. In: International Conference on Collaboration and Technology (pp. 175-191). Springer, Berlin, Heidelberg [GS Search]

Morgan, D. L., \& Krueger, R. A. (1998). Developing questions for focus groups (Vol. 3). Sage. [GS Search]

Nguyen, Q., Huptych, M., \& Rienties, B. (2018). Using Temporal Analytics to Detect Inconsistencies between Learning Design and Student Behaviours. Journal of Learning Analytics, 5(3), 120-135. doi: 10.18608/jla.2018.53.8 [GS Search]

Picciano, A. G. (2002). Beyond student perceptions: Issues of interaction, presence, and performance in an online course. Journal of Asynchronous learning networks, 6(1), 21-40. Disponível em: http://faculty.weber.edu/eamsel/research\%20groups/on-line\%20learning/ picciano\%20(2002).pdf [GS Search]

Plaisant, C. (2005). Information visualization and the challenge of universal usability. In: Exploring geovisualization (pp. 53-82). Elsevier. doi: https://doi.org/10.1016/B978008044531-1/50421-8. [GS Search] 
Relatório ABED (2016). Relatório analítico da aprendizagem a distância no Brasil. ABED. São Paulo, SP. Disponível em: http://abed.org.br/censoead2016/Censo_EAD_2016_portugues.pdf

Silva Junior, C. B., \& Oliveira. I. C. A (2016). Learning analytics: Revisão da literatura e o estado da arte. In Métodos e Tecnologias, 22o Congresso Internaional ABED de Educação a Distância. ABED. São Paulo, SP. Disponível em: http://www.abed.org.br/congresso2016/ trabalhos/329.pdf

Silva, J. C., Brito, A. V., \& Medeiros, F. P. A. (2015). Mapeamento Sistemático da Literatura acadêmico-científica sobre Análise de Redes Sociais aplicada em E-Learning. Revista Brasileira de Informática na Educação, 23(1), 139-148. [GS Search]

Skinner, E., Furrer, C., Marchand, G., \& Kindermann, T. (2008). Engagement and disaffection in the classroom: Part of a larger motivational dynamic?. Journal of educational psychology, 100(4), 765.doi: 10.1037/a0012840 [GS Search]

Ward, M. O., Grinstein, G., \& Keim, D. (2015). Interactive data visualization: foundations, techniques, and applications. AK Peters/CRC Press. [GS Search]

Zielinski, F. D. C., \& Schmitt, M. A. R. (2015). Uma ferramenta gráfica para suporte à atividade docente no Moodle. RENOTE, 13(1). doi: 10.22456/1679-1916.57644 [GS Search] 